\title{
El estudio de las variables demográficas en la Sierra Morena Cordobesa según las fuentes precensales
}

\section{Study of demographic variables in the Sierra Morena of Córdoba according to pre-census sources}

\author{
Ricardo Manuel Luque Revuelto*
}

El análisis de la evolución de la población es un aspecto irrenunciable y básico para entender la ocupación humana del territorio, pues la población es el elemento base sin el cual no se daría el poblamiento y las distintas formas o manifestaciones de este.

Este ensayo de Geografía de la Población se lleva a cabo en una de las grandes unidades subprovinciales de la provincia de Córdoba, la Sierra Morena Cordobesa, un ámbito espacial de gran amplitud, unos 8.326 kilómetros cuadrados de extensión, que abarcan diferentes comarcas y más de unas treintena de municipios, que se encuentran comprendidos entre la margen derecha del Guadalquivir, que a modo eje vertebrador separa la Sierra Morena de la Campiña, y el norte de la provincia de Córdoba.

Hay que advertir que, aún tratándose de una superficie tan extensa, Sierra Morena se individualiza claramente en el conjunto provincial, por su relieve, evolución geológica, suelos, clima e hidrografía, así como por su vegetación y usos del suelo. De la misma manera pensamos que la dinámica demográfica de estos espacios debió de contar con unas características propias. Así, los objetivos del presente trabajo son dos: en primer lugar caracterizar las variables demográficas de la Sierra Morena Cordobesa; y, en segundo lugar, procurar

\footnotetext{
* Departamento de Geografía y Ciencias del Territorio, Universidad de Córdoba (ch1lurer@uco.es).
} 
establecer las semejanzas y las diferencias con el ámbito provincial y regional en el que se inserta.

Surge así una cuestión ineludible de nuestro trabajo: la de definir unos márgenes administrativos en los que inscribir el espacio físico considerado. Ya es conocido el debate abierto sobre el tema comarcal en Andalucía, en la provincia de Córdoba, y desde luego, en las comarcas que comprenden nuestro ámbito subprovincial de estudio. En esta diatriba, se nos hace más patente y certera, a nuestro parecer, la opción de hacer nuestra propia propuesta de comarcalización, respetando las comarcas naturales e históricas del Guadiato y de los Pedroches, y aceptando la unidad o ámbito subprovincial que algunos autores denominan «Municipios Mixtos Sierra-Valle». Municipios estos que, al encontrarse repartido su territorio entre la Campiña y la Sierra, participan de características específicas de ésta, sin renunciar ni a una ni a otra ${ }^{1}$.

Iniciaremos el estudio del componente humano del poblamiento desde el primer tercio del siglo XVI y lo concluiremos a mediados del siglo XIX. La fecha de comienzo viene justificada por la aparición de los primeros recuentos a escala provincial y la final se ha concebido por coincidir con el inicio de los censos periódicos de población; a la vez que comienza una etapa de crecimiento demográfico ininterrumpido y sin precedentes.

La exposición se presenta relacionada en tres apartados: en el primero se analizan las fuentes demográficas disponibles, en el segundo tenemos en cuenta la evolución de la población absoluta y el tercero se ocupa de la dinámica demográfica a lo largo del mismo período.

\section{FUENTES DOCUMENTALES Y BIBLIOGRÁFICAS}

Los datos que reflejan la evolución absoluta de la población tienen su origen en una serie de censos o cómputos que se fueron realizando en distintas épocas y circunstancias históricas. Nos ocuparemos de las fuentes que se han denominado «precensales» o «preestadísticas», caracterizadas por su incons-

\footnotetext{
${ }^{1}$ Así pues nuestra zona de estudio estaría comprendida por la comarca de los Pedroches (Alcaracejos, Añora, Belalcázar, Cardeña, Conquista, Dos Torres, El Guijo, El Viso, Fuente la Lancha, Hinojosa del Duque, Pedroche, Pozoblanco, Santa Eufemia, Torrecampo, Villanueva del Duque, Villaralto y Villanueva de Córdoba); la comarca del Guadiato (Belmez, Espiel, Fuente Obejuna, La Granjuela, Los Blázquez, Obejo, Peñarroya-Pueblonuevo, Valsequillo, Villaharta, Villanueva del Rey y Villaviciosa de Córdoba); y los municipios mixtos Sierra-Valle (Almodóvar del Río, Hornachuelos, Posadas, Adamuz Montoro y Villafranca de Córdoba).
} 
tante elaboración a lo largo de la Edad Moderna y principios de la Edad Contemporánea, a diferencia de las «censales» o «estadísticas», en las que los recuentos efectuados tienen un carácter periódico y sistemático a partir de 1857.

El origen de las llamadas «fuentes precensales» es diverso y no siempre vienen acompañadas de una intención estadística, pudiendo responder a necesidades hacendísticas o de la administración eclesiástica. Tampoco su forma de publicación fue homogénea a lo largo de estos siglos: algunas aparecen como obras con carácter exclusivamente estadístico, otras informaciones aparecen dispersas en manuales generales histórico-geográficos, y en ocasiones, insertas en documentos manuscritos.

Las fuentes precensales que vamos a emplear y que contienen datos relativos a la Sierra de Córdoba son: el Censo de Pecheros ${ }^{2}$ del año 1530, las relaciones eclesiásticas del censo de Tomás González ${ }^{3}$ del año 1587, el Vecindario General de España ${ }^{4}$ del año 1713, el Catastro de Ensenada 5 de 1752, el Censo del Obispado de Córdoba ${ }^{6}$ de 1781, el Censo de Floridablanca ${ }^{7}$ de 1787, y las obras de Miñano ${ }^{8}$ (1826-1828), Casas Deza ${ }^{9}$ (1840) y Madoz ${ }^{10}$ (1847-1849).

Los problemas más frecuentes que ocasionan este tipo de fuentes a la hora de interpretar los datos comienzan con la misma cuestionabilidad o exactitud de los mismos derivada de la propia finalidad de la fuente o del modo en que se obtuvieron los detalles. Pero se dan asimismo otra serie de escollos como es el hecho del excesivo distanciamiento temporal entre algunas fuentes o el hecho de que se relaten los efectivos demográficos en vecinos en vez de en habitantes.

${ }^{2}$ Contadurías Generales. Archivo General de Simancas. Legajo n. ${ }^{\circ} 768$. Publicadas por Cabrera (1978, pp. 298-299).

${ }^{3}$ Censo de las provincias y partidos de la Corona de Castilla. Biblioteca Nacional, Ms. n. ${ }^{\circ}$ 157. Publicadas por González (1829).

${ }^{4}$ Vecindario General de España, 1713. Biblioteca Nacional, Ms n. ${ }^{\circ} 2.274,444$ pp.

${ }^{5}$ Catastro de Ensenada, 1752. Respuestas Generales. N. ${ }^{\circ} 21$ y 22. Archivo Histórico Provincial de Córdoba. Microfilm r. 1-20.

${ }^{6}$ Censo del Obispado de Córdoba, 1781. Publicado por Nieto (1978, pp. 157-171).

7 Censo de Floridablanca, 1789. Biblioteca de la Real Academia de la Historia. Sección varios 9-6200 9-6202. drid.

${ }^{8}$ Miñano, S. de (1826-1828): Diccionario geográfico-estadístico de España y Portugal. Ma-

${ }^{9}$ Ramírez y de las Casas-Deza, L. M. ${ }^{a}$ (1840): Corografía histórico-estadística de la provincia y obispado de Córdoba. Córdoba, Im. de Noguer y Manté, 472 pp.

${ }^{10}$ Madoz, P. (1845): Diccionario geográfico-estadístico-histórico de España y sus posesiones de ultramar. Madrid, Est. literario-tipográfico de P. Madoz y L. Sagasti. 
Así, la irregularidad temporal en las informaciones origina una escasez notoria de las mismas durante el siglo XVI, la carencia absoluta en el siglo XVII y la relativa abundancia de estas en el XVIII, contabilizándose hasta siete en el período comprendido entre 1752 y 1857.

El problema del coeficiente consiste en la búsqueda de un índice multiplicador que convierta los vecinos en habitantes ${ }^{11}$. Con todo, existen tres fuentes que especifican además del número de vecinos, el de habitantes, pudiéndose obtener los coeficientes de equivalencia a partir de sendos datos. Dichas fuentes son las obras de Miñano, Casas Deza y Madoz. Entre estas, la más fiable es la de Casas Deza por tener un carácter exclusivamente provincial, mientras que las otras son de ámbito nacional y pecan por exceso; Madoz emplea un coeficiente multiplicador fijo, el 4, obteniendo de esta forma el número aproximado de habitantes; Miñano, cuyos valores se aproximan más a los de Casas Deza, no resulta muy fiable si tenemos en cuenta las dificultades con que contó para recabar las informaciones pertinentes de la policía y los párrocos y las desmesuradas correcciones que hace a los primeros tomos en el último de ellos.

Según la Corografía de Casas se puede asignar para las distintas comarcas de la Sierra a mediados del siglo xIx un módulo que fluctúa entre 3,7 y 3,9 habitantes por vecino; y que para Miñano oscila entre 3,6 y 4,1. Estas medias ocultan tras de sí una gran variedad comarcal y subcomarcal, pero también descubrimos entre villas muy próximas entre sí, y pertenecientes a la misma comarca, diferencias similares. Lo que nos da a entender lo difícil que resulta establecer un coeficiente multiplicador para un área tan extensa, no pudiéndose aceptar fácilmente resultados globales. Cada núcleo de población, como consecuencia de las circunstancias de aislamiento, malas comunicaciones, autarquía agraria o autoabastecimiento tendría, de igual manera, una dinámica demográfica propia. El hecho de que no exista un crecimiento vegetativo similar (cuadro 1) entre zonas próximas viene a corroborar esta afirmación. Por todo ello cabe hablar de una «autarquía demográfica» que se sumaría a la ya existente de tipo económico o agrario.

Tampoco el coeficiente vale para hacer comparaciones en el tiempo, ni siquiera en fechas próximas pues como afirma Vilar: «de la noche a la mañana una peste puede hacer que el número de fuegos siga constante pero que la po-

${ }^{11}$ En nuestro caso no entraremos en la controversia que origina este clásico tema de la demografía histórica. Los estudios sobre el tema son numerosos, pero se encuentra una buena síntesis explicativa en el artículo de Bustelo (1973). 
blación varíe notablemente» (Bustelo, 1973). Por consiguiente, parece lo más lógico prescindir de los citados índices de conversión, en la medida de lo posible, y procurar atenernos a los datos de población tal y como figuren en las fuentes, bien sea en vecinos o en habitantes.

\section{LA EVOLUCIÓN DEMOGRÁFICA}

El número de vecinos de la Sierra de Córdoba se incremento en un 211\% entre las fechas de 1530 y 1847 , pasando de 9.151 a 19.304 . Pero el crecimiento experimentado en un período de tiempo tan extenso no fue constante ni en el tiempo ni en las distintas comarcas. Se aprecian más afinidades a escala global o interregional que entre las distintas comarcas que integran el espacio analizado.

Las principales tendencias demográficas, en general, que caracterizan esta evolución a lo largo de tres siglos son de forma somera las siguientes:

- Aumento sostenido y moderado en el siglo XVI.

- Aguda crisis demográfica a lo largo del siglo XVII.

- Salida de la crisis e ininterrumpido crecimiento en el siglo XVIII.

- Crecimiento notorio en la primera mitad del XIX, pero con importantes diferencias comarcales.

En líneas generales este modelo demográfico es coincidente con el descrito para España y Andalucía por autores como Nadal (1988), Nicolau (1991) o Pérez García (1995).

A continuación vamos a centrarnos en cada una de estas etapas tratando de caracterizar de manera más explícita cada una de ellas.

\section{La expansión demográfica del siglo XVI}

El período comprendido entre 1530 y 1587 arroja un balance muy positivo, creciendo la población serrana entre ambas fechas un $24 \%$, esto es, a un ritmo del $0,42 \%$ anual, suponiendo que fuese homogéneo a lo largo del tiempo comprendido. A pesar de todo, esta cifra estaría muy por debajo de las que Fortea (1981, p. 123) nos ofrece para la Campiña, cuya población aumenta un $0,97 \%$ anual entre 1530 y 1561; o las que del estudio de Nadal (1988, p. 41) se infieren respectivamente en el período 1530-1591 para Andalucía, la Corona de Castilla y España continental: 0,65\%, 0,70\% y 0,67\%. 
Los datos evidencian que la expansión demográfica contó con más inconvenientes en las economías ganadero-artesanales del norte de la provincia que en las agrícolas del sur; a lo que se sumaban las dificultades de explotación de la zona debido al escaso éxito de la repoblación y a la reducida densidad de las distintas comarcas de Sierra Morena: 5,11 habitantes por $\mathrm{km}^{2}$ frente a los 10,04 del Reino de Córdoba ${ }^{12}$.

Aunque la nota predominante de la demografía serrana fue positiva, si bien inferior a las medias provinciales, regionales y nacionales, son notorias las diferencias intercomarcales y entre las distintas villas tal y como se puede apreciar en los cuadros 2 y $3^{13}$. Destaca el conjunto de Municipios Mixtos que sobrepasa el índice 160 con relación al 100 de 1530. La población absoluta registró un incremento de 1.118 vecinos saldándose la tasa de crecimiento con un 6,3\% anual. Con una tasa de crecimiento algo inferior, un 3,3\%o le sigue la comarca de los Pedroches que alcanza el índice 119 pasando la población de 5.502 a 6.525 vecinos. El crecimiento más exiguo tuvo lugar en la Cuenca del Guadiato, con el 1,7\%o. Su número de vecinos sólo aumento en 173 en los 57 años comprendidos entre 1530 y 1587.

La explicación de los distintos comportamientos demográficos y las desigualdades internas que aparecen en cada una de las comarcas es preciso buscarla en la existencia de factores históricos y agronómicos desiguales.

Los municipios que se localizan en los límites de Sierra Morena con el Valle del Guadalquivir presentan unas características demográficas similares a los de la Campiña. Es necesario tener en cuenta que los términos septentrionales de estos municipios estaban prácticamente despoblados y que los núcleos de población se asientan en las proximidades del río Guadalquivir sobre un terrazgo agrícola que presenta un mayor potencial agronómico. El distanciamiento relativo en los niveles de poblamiento respecto a los asentamientos

12 Según Fortea (1981, p. 84), Cabrera (1978, pp. 301-302) da unos valores parecidos aunque inferiores, no superando la mitad de la media provincial la Sierra de Córdoba. Según nuestros cálculos, y teniendo en cuenta la demarcación ya expuesta de la Sierra de Córdoba, la densidad de vecinos por $\mathrm{km}^{2}$ fue de 1,00 en 1530 y de 1,25 en 1587 .

13 Nota: El signo + que precede en los cuadros a algunas cifras indica que el valor reseñado debiera ser superior. Las lagunas existentes en algunas localidades, o en series de datos que no llegan a completar el año, explican este hecho. Las cifras de habitantes de 1781 y 1787 se han reducido previamente a vecinos utilizando como coeficiente una media variable de cada comarca confeccionada a partir de los datos de Miñano, Casas Deza y Madoz, que especifican además del número de vecinos el de habitantes, pudiéndose obtener los coeficientes de equivalencia a partir de sendos datos. Así, para el Guadiato se emplea el módulo 3,95, para los Pedroches el 3,93 y para los Municipios Mixtos el 3,83. 


\section{FIGURA 1}

\section{INCREMENTO DEMOGRÁFICO EN 1587}

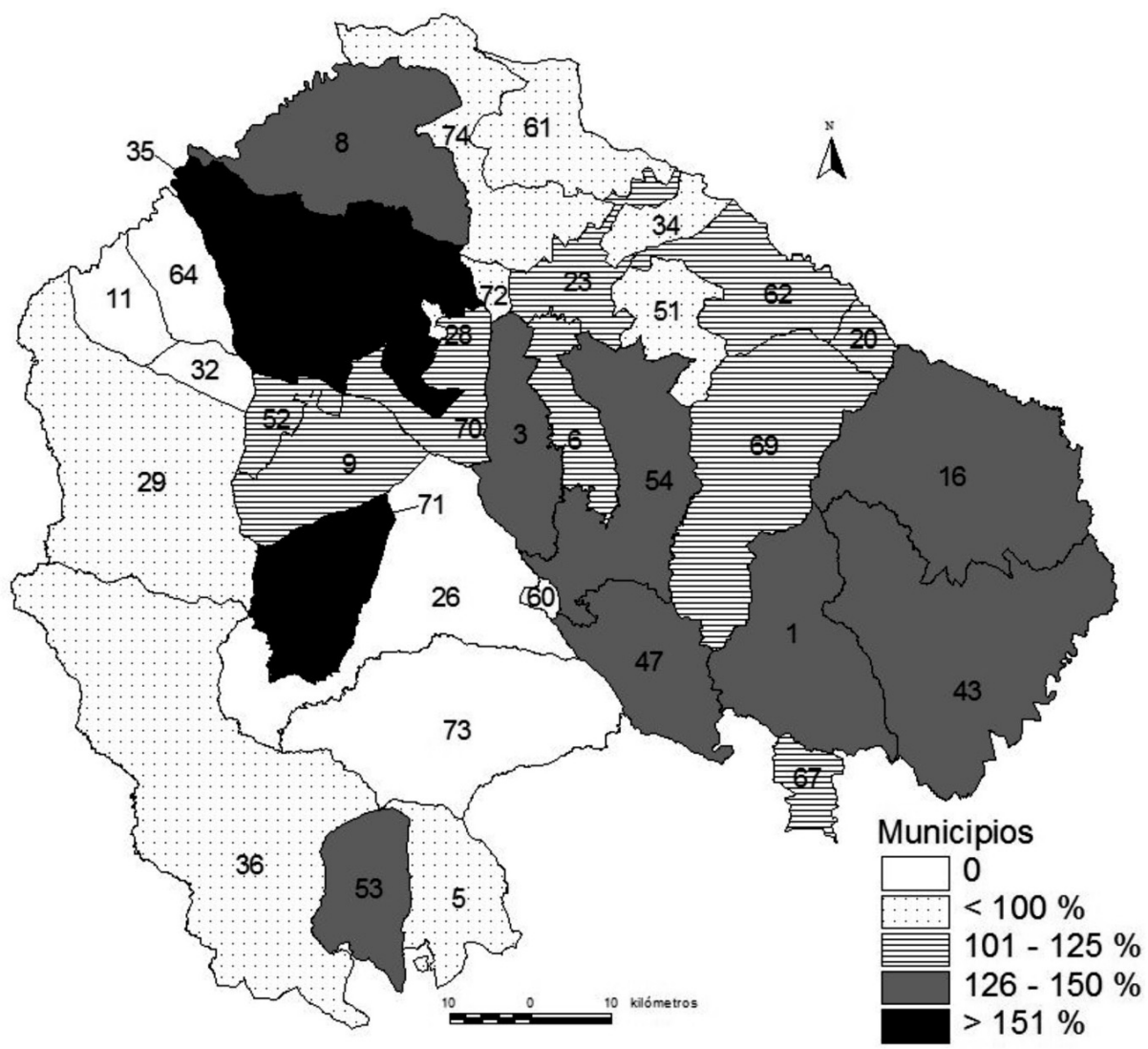

Nota 1: Números índice con base $1530=100$.

Nota 2: Comarca de los Pedroches: Alcaracejos (3), Añora (6), Belalcázar (8), Cardeña (16, Venta de Montoro), Conquista (20), Dos Torres (26, Torrefranca y Torremilano), El Guijo (34), El Viso (74), Fuente la Lancha (28), Hinojosa del Duque (35), Pedroche (51), Pozoblanco (54), Santa Eufemia (61), Torrecampo (62), Villanueva del Duque (70), Villaralto (72) y Villanueva de Córdoba (69). Comarca del Guadiato: Belmez (9), Espiel (26), Fuente Obejuna (29), La Granjuela (32), Los Blázquez (11), Obejo (47), PeñarroyaPueblonuevo (52, dependiente de Belmez), Valsequillo (64), Villaharta (60), Villanueva del Rey (71) y Villaviciosa de Córdoba (73). Municipios Mixtos Sierra-Valle: Almodóvar del Río (5), Hornachuelos (36), Posadas (53), Adamuz (1), Montoro (43) y Villafranca de Córdoba (67).

Fuente: elaboración propia a partir del Censo de Pecheros y el de Tomás González. 
enclavados en el curso del Guadiato o en los Pedroches se debe al mayor crecimiento de las villas situadas en el Valle, entre las que se incluyen las que se encuentran entre el extremo sur de la Sierra y el Guadalquivir. No hay poblamiento disperso en esta parte sur de la Sierra. Pero este crecimiento no es generalizado en todas ellas, destacando sólo en el caso de dos villas situadas una en el extremo occidental y la otra en el oriental, nos referimos a Montoro y Posadas, que ven incrementado el número de sus habitantes en más de un tercio. Los núcleos situados entre estas y la capital ${ }^{14}$ permanecen estancados (Hornachuelos), experimentan un ligero retroceso (Adamuz) o como en el caso de Almodóvar del Río pierden más de un cuarto de su población total en el período estudiado. La densidad media de población en esta comarca se sitúa en 0,66 vecinos $/ \mathrm{km}^{2}$ en 1530 y 1,02 en 1587 .

Los Pedroches experimentan un crecimiento moderado, inferior al del conjunto de las villas del piedemonte de Sierra Morena, pero algo superior a los municipios del Guadiato. Resulta ser además la que mayor concentración de vecinos por $\mathrm{km}^{2}$ posee en toda la Sierra y en ambas fechas. Era de 1,77 en 1530 y de 2,40 en 1587. En este caso también son evidentes las diferencias de evolución en cada una de las subcomarcas y en sus respectivas villas. Valle Buenestado (1985, pp. 290 y ss.) ha estudiado con detenimiento estas disparidades así como las causas que concurren en ello, llegando a la conclusión de que no se puede asegurar una relación unívoca entre el régimen realengo o señorial y la evolución demográfica; sino que en todo caso son más influyentes las estructuras agrarias y la actuación territorial que desarrolla cada régimen. De esta forma el condado de Belalcázar fue la que experimentó mayor crecimiento, llegando al índice 137, que se corresponde con un crecimiento anual del 5,4\%o, debido a su tardía señorialización ${ }^{15}$ y a la no existencia de una nobleza monopolizadora como fuera la de Santa Eufemia. La existencia de otros títulos nobiliarios y la influencia del Cabildo Municipal de Córdoba frenaron las usurpaciones señoriales permitiendo la existencia de bienes comunales, principal fuente de subsistencia de las economías campesinas. La densidad de población para ambas fechas de estudio fue respectivamente del 1,62 y 2,21 vecinos por $\mathrm{km}^{2}$.

\footnotetext{
${ }^{14}$ Incluso la propia capital cordobesa registró notables vacilaciones demográficas (Flores, 2005, p. 104).

${ }^{15}$ El área señorializada de la Sierra de Córdoba se concentraba en los Pedroches y estaba formada por el Condado de Santa Eufemia (Santa Eufemia, El Guijo y El Viso) y el Condado de Belalcázar (Belalcázar, Hinojosa y Villanueva del Duque).
} 
El polo opuesto fue el otro señorío, el de Santa Eufemia que sufrió un importante descenso de población, pasando de un índice 100 a 86 a finales de la centuria, con un ritmo negativo de crecimiento anual del 2,3\%o. La causa inmediata fue la usurpación por parte del noble, titular del señorío, de las tres cuartas partes del territorio. Este hecho unido a la escasa calidad agronómica de las tierras aumentó la presión sobre los campesinos que se vieron obligados a emigrar en busca de nuevos espacios en la zona de realengo. Así, pasó de tener la densidad media más baja de los Pedroches en 1530, 1,25 vecinos por $\mathrm{km}^{2}$, a una aún más inferior en $1587,1,08$.

En un estadio intermedio se encontraba la comarca de realengo con un promedio de crecimiento anual del 2,3\% y la densidad media más elevada: 2,09 y 2,42, en 1530 y 1587, respectivamente. En ella se produjo también un desplazamiento de vecinos hacia los baldíos que se ubicaban en un extenso y denso bosque mediterráneo en el que apenas se habían iniciado las tareas de ahuecamiento. Los nuevos territorios una vez desbrozados pasaban a engrosar los bienes del común que sirvieron como término y base para el establecimiento de las nuevas villas emancipadas de la jurisdicción de Pedroche andando el siglo XVI (Ocaña, 1962, pp. 148 y ss.).

Pero como ya observamos, a las diferencias intracomarcales es preciso añadir la existente entre unas villas y otras. Es destacable el hecho de que no son las capitales históricas de cada subcomarca las que experimenten un crecimiento mayor. Así en el condado de Belalcázar, Hinojosa supera a Belalcázar en más de 30 puntos. En el de Santa Eufemia, la capital se reduce al índice 84 mientras que su vecina Torrefranca alcanza el 125. En la subcomarca de realengo es señero el crecimiento de Pozoblanco seguido de Alcaracejos y Villanueva de Córdoba, ello en detrimento de Pedroche que desciende al índice 61.

Los municipios de la Cuenca del Guadiato son durante el período de 15301587 los que ensayan un menor crecimiento, tan sólo un 10\%. Además, es de las tres comarcas, la menos poblada: sólo 0,59 vecinos por $\mathrm{km}^{2}$ en la primera fecha y 0,65 al final del período. En ellos se concentra la población en el curso alto del Guadiato en los actuales términos de Fuente Obejuna, Peñarroya-Pueblonuevo, Belmez, Los Blázquez, Valsequillo y la Granjuela, con un total de 1.613 vecinos en 1530 de los 1.826 que habitaban la comarca, es decir casi el $90 \%$. La densidad de población en la primera zona era del 0,93 mientras que en el resto era sólo de 0,16. La villa más importante era la de Fuente Obejuna que experimenta un ligero retroceso, contando con 1.312 vecinos en 1587 . La segunda en número de vecinos fue Villanueva del Rey con 321 para la misma fecha y con un índice del crecimiento del 214 respecto al 100 del año 1530, el más elevado de las tres comarcas. Así, al igual que en los Pedroches, no será la 
capital histórica la que registre el mayor crecimiento sino una de sus vecinas. Le sigue Belmez con 284 vecinos en 1587 y Obejo con 82.

En resumidas cuentas, el poblamiento de Sierra Morena resulta bastante desequilibrado. De las 26 villas que existían a finales de siglo, 18 se ubican al norte de un paralelo que podemos dibujar entre Villanueva de Córdoba y Fuente Obejuna. En esta amplia zona se concentra más del 70\% $(71,72)$ de la población serrana total. Al sur de esta línea la despoblación era absoluta a excepción de los núcleos de Villanueva del Rey, Obejo y de las ventas que jalonaban el camino entre Adamuz y Conquista. Ya en el piedemonte de Sierra Morena y en las proximidades del Guadalquivir volvemos a encontrar indicios de un poblamiento más acentuado y escalonado a lo largo de esta divisoria, que está integrado por unos 2.799 vecinos, el 24,72 \% de la población serrana.

La estructura del poblamiento serrano está prácticamente definida a finales del siglo Xvi, a falta de algunos añadidos como es la aparición de las villas de Villaharta y Villaviciosa en el siglo XviII. La distribución de la población surgida de las circunstancias analizadas fijaron definitivamente el hábitat de las distintas comarcas que integran la Sierra de Córdoba, contribuyendo a una jerarquía que se mantiene en la actualidad y que en buena parte está impregnada de un significado geomorfológico, dado que las poblaciones, evitando los relieves más abruptos, se localizan en la penillanura pedrocheña, en la cuenca del Guadiato o en el piedemonte de Sierra Morena.

\section{La crisis demográfica del siglo XVII}

La siguiente etapa que viene a continuar el llamado «ciclo demográfico antiguo» es la que abarca desde 1587 hasta 1713. Este periodo se va a caracterizar, a diferencia del anterior, por una evolución demográfica regresiva que perduraría hasta mediados del siglo XviII.

Se puede afirmar que, en líneas generales, el desarrollo de la población serrana cordobesa fue similar al experimentado en el resto de la Península ${ }^{16}$. Las cifras totales arrojan una pérdida de 3.443 vecinos, en cifras relativas 36 puntos, entre ambas fechas. Es decir se pasa de 11.464 vecinos en 1587 a 8.021 en 1713, año en que se efectúa el Vecindario General de España. El crecimiento de la población sería negativo y a razón del 2,9\%o anual, perdiéndose entre ambos periodos un $30 \%$ de la población global.

${ }^{16}$ En este sentido Ponsot afirma que: «la Sierra Morena se vacía de hombres», de la misma manera que muchas otras localidades campiñesas (Ponsot, 1986, pp. XVI y ss.). 
Estos datos pueden parecer algo desmesurados, máxime si observamos las cifras que refleja en Catastro de Ensenada en 1752. Las diferencias tan marcadas no parecen concordar, lo que nos hace poner en entredicho la validez de dichos datos. En efecto el censo de Tomás González parece pecar por exceso, como opinan Ruiz Martín (1967, p. 196) o Fernández Álvarez (1979. pp. 346 y ss.), mientras que el de 1713 lo hace por defecto. Domínguez Ortiz (1981, p. 130) cree que puede esconder ocultaciones superiores al 20\% dependiendo de las distintas villas y áreas geográficas. Por consiguiente, si tenemos en

\section{FIGURA 2}

INCREMENTO DEMOGRÁFICO EN 1713. NÚMEROS ÍNDICE CON BASE $1530=100$

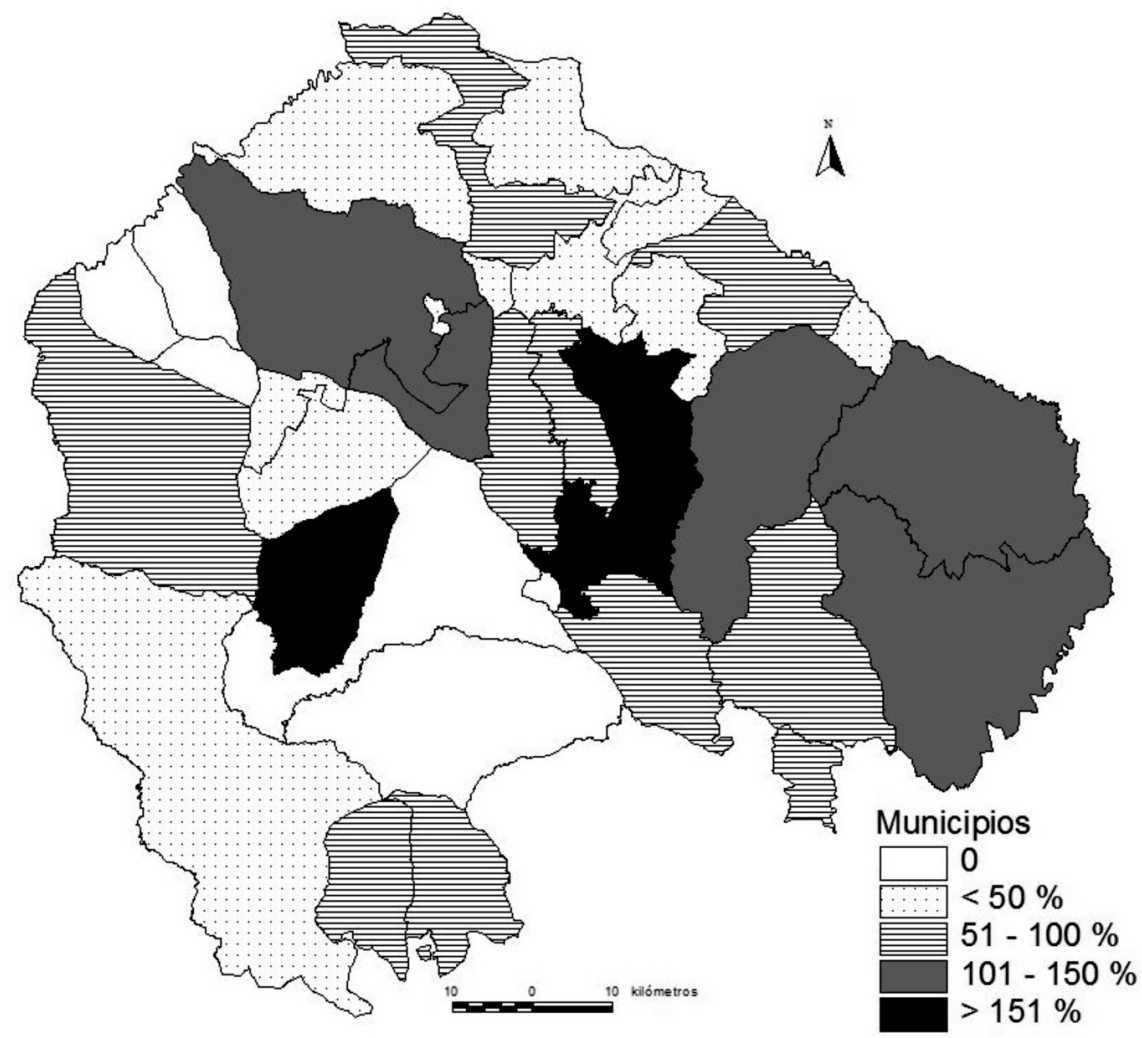

Nota: Números índice con base $1530=100$.

Fuente: elaboración propia a partir del Censo de Pecheros y el Vecindario General de España. 
cuenta dichas salvedades, y atendemos al estudio de los movimientos naturales parece evidente que las cifras absolutas parecen algo o bastante matizables.

Analizando los datos en función de los distintos ámbitos que componen la Sierra Morena cordobesa podemos apreciar que las desigualdades son bastante evidentes. Si comparamos las cifras relativas la aserción anterior resulta evidente, la crisis demográfica más aguda fue la padecida por la comarca de la Cuenca del Guadiato, seguida por la de los Pedroches, las cuales ven reducido el índice 100 del año 1530 a 76 y 86 respectivamente. Los Municipios Mixtos se mantienen en la cifra de 104. Pero si comparásemos estos datos con la última fecha de la que tenemos información demográfica anterior a 1713, es decir la 1587, vemos como las comarcas del Guadiato y Municipios Mixtos han perdido respectivamente un 31\% y un 33\% de población, mientras que los Pedroches sólo un 28\%. De estas comparaciones podemos concluir que en los Municipios Mixtos el crecimiento durante la etapa anterior fue bastante elevado pero también afectó la crisis en mayor medida. En los Pedroches con un crecimiento intermedio anteriormente, la crisis no fue tan virulenta como en las otras dos. Finalmente en el Guadiato, la menos dinámica demográficamente, la crisis fue similar en crudeza a la del piedemonte de la sierra cordobesa.

Pero si considerásemos, en un análisis más pormenorizado, cada una de las villas veríamos que, de nuevo, lo hasta ahora analizado queda en entredicho, pues son las villas más importantes o las que ostentan la capitalidad histórica de cada comarca o subcomarca las que sufren los retrocesos mayores con respecto a las medias comarcales. A excepción de Montoro, es evidente en el caso de Fuente Obejuna, Posadas, Pedroche, Belalcázar y particularmente trágico en Santa Eufemia. Todo ello no hace sino reafirmar la tendencia centrifuga de la población dentro de cada una de las comarcas, que se iniciara en el siglo XVI y que se fue consolidando en el siguiente. Así los fenómenos migratorios juegan un papel fundamental, ocasionando no solo el despoblamiento, sino el abandono de tierras y la consecuente paralización del proceso roturador iniciado en la etapa anterior. Dicha manifestación no es exclusiva de nuestra zona de estudio sino que afectó a buena parte de Andalucía Occidental (Bernal, 1981, pp. 193 y ss.).

Únicos son los casos de Pozoblanco y de Villanueva de Córdoba, pues de las 21 villas consideradas, solo estas dos fueron protagonistas de un considerable crecimiento durante esta etapa. Las causas no son otras que el intenso y ventajoso aprovechamiento de los bienes comunales de las Siete Villas derivado de su céntrica situación; y, por otro, la ubicación y desarrollo en sus cascos urbanos de numerosas industrias textiles que transformaron dichas villas en centros comerciales de primera categoría a escala regional (Fortea, 1981, 
pp. 281, 388 y ss.). Todo ello en un contexto espacial en el que se produce una considerable reducción en la producción de cereales en Sierra Morena y en la Baja Andalucía en general, como demuestra la disminución en la percepción de los diezmos de dicho producto (Ponsot, 1986, pp. XVIII).

\section{El ascenso demográfico del siglo XVIII}

Desde principios del siglo XVIII hasta mediados del siglo XIX la población serrana se duplicó, pasando de 8.021 a 19.304 vecinos; lo que equivaldría a un ritmo de crecimiento anual del 10,3\%o. Pero, como muestran las fuentes, el proceder demográfico no fue constante en este dilatado periodo de tiempo, pudiéndose distinguir dos momentos caracterizados por una desigual intensidad del ritmo evolutivo. Así distinguimos el periodo comprendido entre 1713 a 1787 y el que abarca desde esa fecha hasta 1849 .

A lo largo del siglo XVIII se produjo un ascenso demográfico sin precedentes en España y en toda Europa. La Sierra de Córdoba también fue partícipe de este espectacular crecimiento, duplicándose la población existente a principios de siglo. Las causas también son comunes: en principio se produce un gran impulso en las actividades agrarias (Ponsot, 1986, pp. XVIII y ss.), que podría haber sido el motor de la expansión demográfica. Por otro lado se registra una disminución considerable de los grandes contagios epidémicos como la peste, que unido al uso de medicamentos como la quinina o la inoculación contra la viruela, permitieron reducir drásticamente la sobremortalidad catastrófica.

Todos los factores expuestos no operaban siempre en el mismo sentido ni con la misma intensidad, pues a finales de la centuria la tendencia parece invertirse, ya que en todas las comarcas mariánicas los índices adquieren valores negativos. Además, aparece la amenaza de un nuevo contagio: el cólera morbo o fiebre amarilla que entraba por el sur de Andalucía procedente de Asia.

En conjunto se paso del índice 88 de 1713 al 164 de 1781 y sólo seis años más tarde al 161. Pero hay que tener en cuenta que las cifras del Censo de Floridablanca pecan por defecto a causa de la ocultación de los propios habitantes por temor a verse alistados en el ejército y al efectuarse el censo en unas fechas en las que la población se encontraba muy mermada tras «una epidemia casi general de tercianas y fiebres pútridas» (Romero 1973, p. 139).

Si descendemos al análisis de las distintas comarcas se reconoce, al igual que en la etapa anterior, el mayor y más uniforme crecimiento de las villas del piedemonte de Sierra Morena, a las cuales no parece afectar la tendencia regre- 
FIGURA 3

\section{INCREMENTO DEMOGRÁFICO EN 1787}

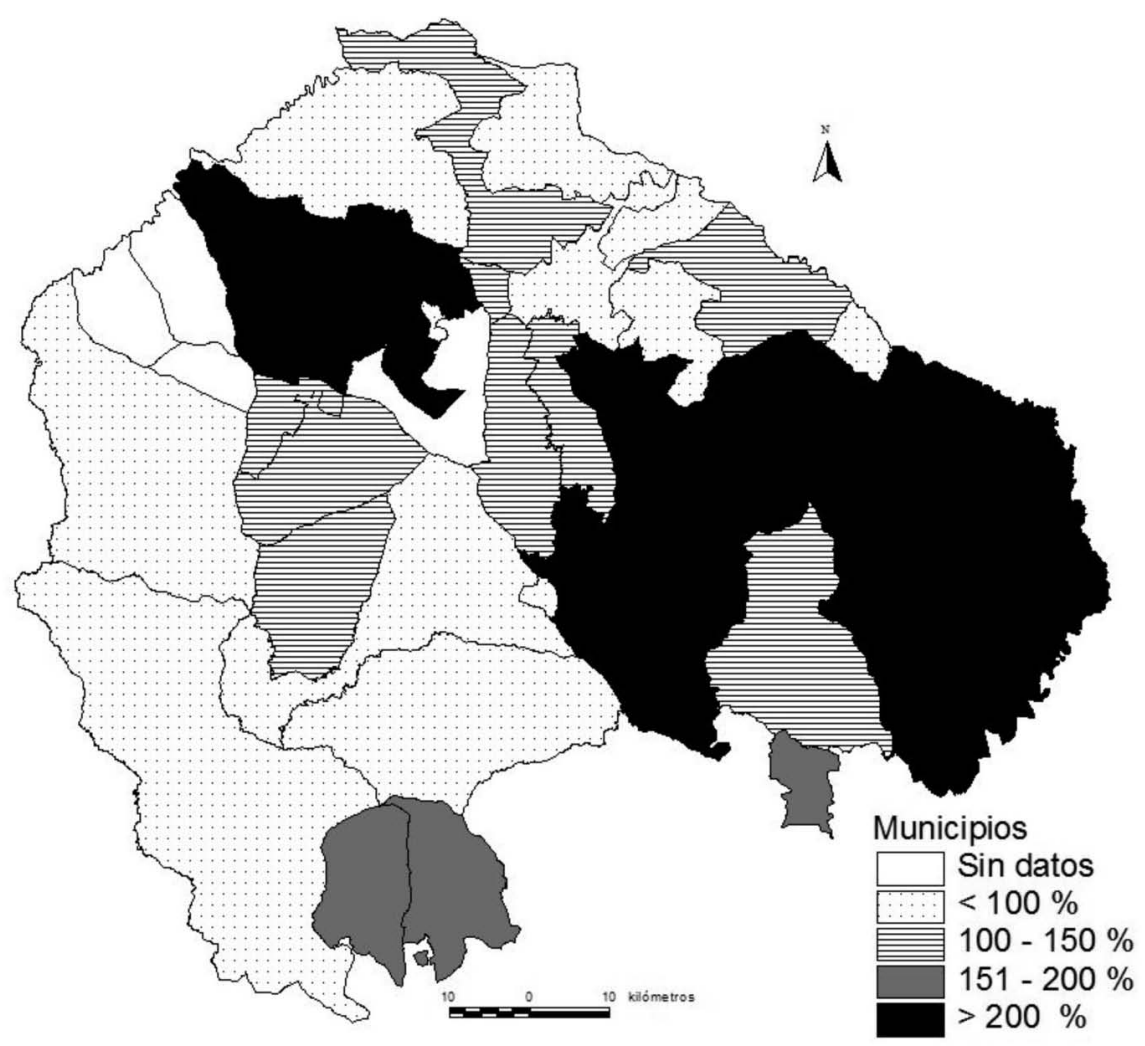

Nota: Números índice con base $1530=100$.

Fuente: elaboración propia a partir del Censo de Pecheros y el Censo de Floridablanca.

siva de finales de siglo, sino todo lo contrario, la población alcanza el índice 238 en 1787 frente al 210 de 1781. La comarca de los Pedroches y la del Guadiato le fueron a la zaga, no alcanzando el índice 200 y contando con que a finales de siglo padecieron la mencionada crisis. Ambas parecen tener incrementos similares, aunque la del Guadiato llega a finales de siglo con menos contingentes demográficos, debido al inferior nivel de partida. Otra disimilitud en estas comarcas estriba en el hecho de que existe una inflexión entre 1752 y 1787, clara en las subcomarcas de señorío de los Pedroches, mientras 
que no se dio en el Guadiato ni en la subcomarca de realengo de los Pedroches. Dicha fase de estancamiento y regresión se explica por error no detectado en los censos o a causa del intento de aplicar un coeficiente divisor para adecuar las cifras de habitantes de 1781 a vecinos con objeto de compararlas a las de 1713 y 1752. No obstante la regresión demográfica fue real tal y como se observa en los bautismos de Hinojosa del Duque las causas están ligadas a las estructuras agrarias y ecológicas de cada zona (Valle, 1985, pp. XX) estas fechas debemos reseñar la aparición como villas en 1778 de Villaviciosa de Córdoba y de Espiel que se desligan de la jurisdicción de Villanueva del Rey. La primera con 823 habitantes, la segunda con 966 ya en 1781. Las villas más dinámicas demográficamente en el Guadiato fueron las de Belmez y la de Obejo, ésta estuvo a punto de cuadriplicar el número de sus efectivos y Belmez los triplicaba. Las villas próximas al Guadalquivir duplican su población en casi todos los casos a excepción de Hornachuelos, pero en ningún caso se triplican.

A pocos años de terminar la centuria la densidad de población de la sierra cordobesa se había elevado considerablemente, si comparamos con etapas anteriores, hasta alcanzar los $6,5 \mathrm{hab} / \mathrm{km}^{2}$. Los Pedroches tenían no obstante aproximadamente $10 \mathrm{hab} / \mathrm{km}^{2}$, mientras que el piedemonte de Sierra Morena 6,18 y la comarca del Guadiato sólo 3,07. Todos los datos contrastan con la que se calcula para el Reino de Córdoba que según Romero (1973, p. 137) era de $17,2 \mathrm{hab} / \mathrm{km}^{2}$.

\section{El desigual crecimiento durante la primera mitad del siglo XIX}

Desde finales del siglo XVIII hasta mediados del XIX la población de la Sierra siguió un ritmo creciente, pasando de 58.130 a 77.210 habitantes. El ímpetu demográfico de la etapa anterior quedó cercenado primero por la epidemia de fiebre amarilla de 1803-1804 y seguidamente por la devastación originada por la Guerra de Independencia.

El crecimiento anual estimado es del 5,3\%o anual. No obstante el aumento de la población total no siguió un ritmo constante ni cronológica ni espacialmente. Las anomalías son frecuentes si comparamos los datos del crecimiento absoluto de la población con las de los movimientos naturales (cuadro 1). Además las distintas fuentes de información que jalonan el periodo muestran evidentes irregularidades.

En esta etapa ya contamos con mayor número de fuentes demográficas que en las anteriores y se reducen considerablemente los años transcurridos entre 
FIGURA 4

INCREMENTO DEMOGRÁFICO EN 1847

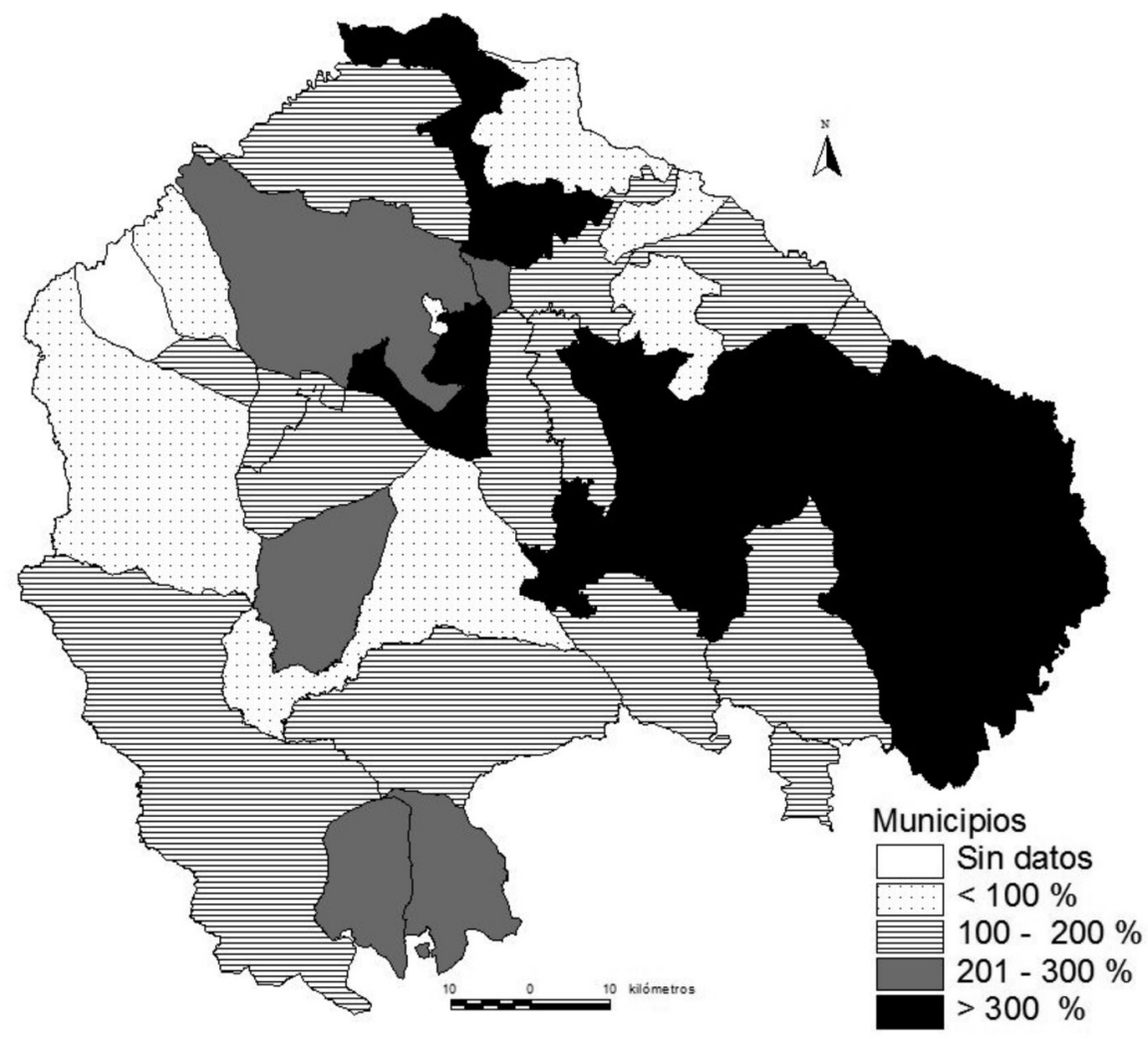

Nota: Números índice con base $1530=100$.

Fuente: elaboración propia a partir del Censo de Pecheros y el Diccionario de Madoz.

un recuento y otro, aunque dichos periodos no son homogéneos entre sí. Pero el mayor problema a la hora de valorar los datos reside en las numerosas inexactitudes que aquellos contienen, hecho que se constata al compararlos entre sí.

La Corografía histórico-estadística de la provincia y obispado de Córdoba de Ramírez de las Casas Deza parece ser la que contiene los datos más certeros, por cuanto se confeccionó a escala provincial y su autor resultó ser un buen conocedor de la geografía e historia cordobesa. Además, si relacionamos sus datos con otras fuentes más fiables como el Censo de 1857, obtenemos un índice de crecimiento que resultaría ser bastante plausible. 
FIGURA 5

EVOLUCIÓN DEMOGRÁFICA POR COMARCAS 1530-1849

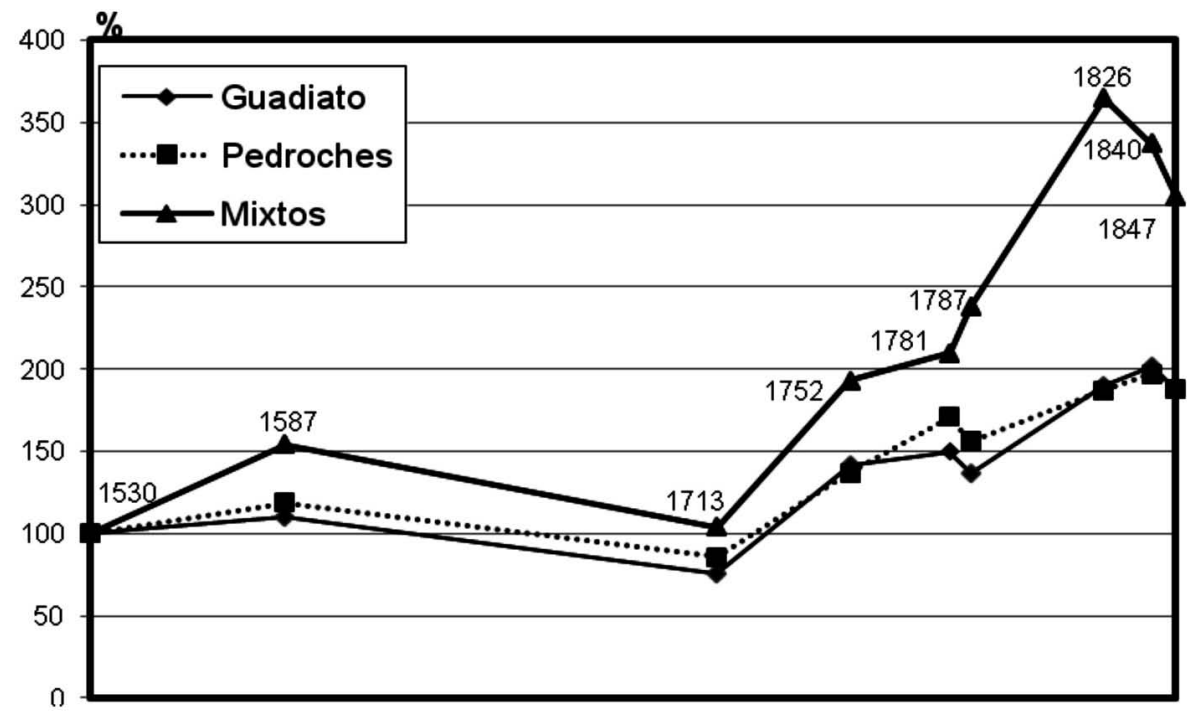

Nota: Números índice con base $1530=100$.

Fuente: elaboración propia a partir de las fuentes precensales referidas.

En cambio, las obras de Miñano y Madoz contienen mayor número de errores. El primero reconoce al inicio del tomo X del Diccionario GeográficoEstadístico las dificultades, así como «los muchos errores de pluma» acaecidos durante su elaboración. En el tomo XI parecen subsanados bastantes de ellos, pero las cifras siguen pareciendo bastante disparatadas, sobre todo las referentes al número de habitantes (81.887). La de vecinos encajan mejor si las comparamos con los Censos de 1781 y 1787. Madoz en su obra parece pecar por defecto, así si comparamos el número de vecinos con los de 1840 resultaría un crecimiento negativo del $6,5 \%$ y si comparamos los habitantes con los del Censo de 1857 se infiere un incremento de $21,8 \%$ de la población, algo imposible en tan corto lapso de tiempo, máxime si tenemos en cuenta que en el año de 1855 se produjo un bache demográfico a causa de una epidemia de cólera. El error parece ser mayor en el número de vecinos que en el de habitantes, además parece que la cifra de aquellos para cada una de las villas ha sido obtenida utilizando el coeficiente 4 en todos los casos. 
Por comarcas (figura 5), las que menos crecieron, y que al final del periodo se igualan en un índice 188, fueron la del Guadiato y la de los Pedroches. Las villas del piedemonte de Sierra Morena, en cambio, superaron el índice 300 poniéndose a la cabeza las de Montoro y Posadas. La comarca del Guadiato, superando las dificultades de la etapa precedente, entra en una fase expansiva, aunque jalonada de varias depresiones, pasando de 9.459 a 13.656 habitantes. Pese a todo era la menos poblada, con $4,4 \mathrm{hab} / \mathrm{km}^{2}$ al final del periodo. El compás de crecimiento ya no fue tan elevado y algunas como Espiel, Obejo o Belmez experimentan cierto retroceso.

Los Pedroches ven aminorarse también su ritmo de crecimiento, debido a una saturación demográfica, al rozarse los límites potenciales de los distintos aprovechamientos agrarios de la comarca. La densidad de población alcanzó los $13,3 \mathrm{hab} / \mathrm{km}^{2}$. Las subcomarcas más dinámicas en este periodo fueron las de señorío, una vez superadas las dificultades pasadas, sus habitantes accedieron a la explotación de sus términos, hecho facilitado por el retorno de la Mesta y la aparición de nuevos contratos de arrendamiento. Las villas de realengo comenzaron en cambio a dar muestras en sus terrazgos de un progresivo agotamiento, ocasionado por la sobreexplotación del arbolado y el exceso de labranza y rozas.

Fueron, en cambio, los denominados Municipios Mixtos los que ven aumentar su población en casi un tercio, concretamente un $24 \%$, entre las fechas de referencia; el mayor crecimiento se produjo en las villas de Almodóvar y Montoro, que ya supera los 10.000 habitantes.

\section{LOS MOVIMIENTOS NATURALES DE POBLACIÓN}

Tras estudiar en conjunto la evolución de los efectivos humanos globales y establecer una serie de etapas en función de la misma, es conveniente descender al análisis de la propia dinámica natural para poder explicar la evolución demográfica de forma más penetrante y para poder perfilar aquellas cuestiones que se ocultaban tras los datos generales.

Van a ser los Registros Parroquiales la fuente que de forma casi exclusiva y parcial proporcione datos desde mediados del siglo XVI hasta el año 1870. A partir de esta fecha lo harán los libros del Registro Civil.

Los archivos parroquiales que cuentan con la documentación referida a este periodo son ciertamente pocos. En el Guadiato disponemos de los de Fuente Obejuna, Belmez y Villanueva del Rey, que resultan ser una muestra bastante significativa de la comarca. Para los Pedroches tenemos los datos de Hinojosa del Duque y Villanueva de Córdoba, y la interpretación de los mis- 


\section{CuAdro 1}

EVOLUCIÓN DE LAS TASAS DE NATALIDAD, MORTALIDAD Y CRECIMIENTO VEGETATIVO (\%o)

\begin{tabular}{|c|c|c|c|c|c|c|c|c|c|c|}
\hline & & 1530 & 1587 & 1713 & 1752 & 1781 & 1787 & 1826 & 1840 & 1847 \\
\hline \multirow{3}{*}{ Belmez } & $\mathrm{TN}$ & - & 32,98 & 54,09 & 29,58 & 56,38 & 38,51 & 38,35 & 36,22 & 34,40 \\
\hline & $\mathrm{TM}$ & 8,88 & - & - & 24,77 & 43,12 & 30,58 & 26,28 & 26,28 & 26,41 \\
\hline & $\mathrm{CV}$ & - & - & - & 4,82 & 13,27 & 7,93 & 12,07 & 9,94 & 7,99 \\
\hline \multirow{3}{*}{$\begin{array}{l}\text { Fuente } \\
\text { Obejuna }\end{array}$} & $\mathrm{TN}$ & - & 22,38 & 20,19 & 17,98 & 12,83 & 17,65 & 21,01 & 20,94 & 21,03 \\
\hline & $\mathrm{TM}$ & - & 6,37 & 14,46 & 24,46 & 10,37 & 13,48 & 16,71 & 12,75 & 19,74 \\
\hline & $\mathrm{CV}$ & - & 16,02 & 5,73 & $-6,49$ & 2,46 & 4,18 & 4,30 & 8,19 & 1,29 \\
\hline \multirow{3}{*}{$\begin{array}{l}\text { Hinojosa del } \\
\text { Duque }\end{array}$} & TN & - & 49,54 & 53,54 & 35,76 & 34,22 & 41,96 & 31,76 & 41,97 & 53,82 \\
\hline & $\mathrm{TM}$ & - & - & - & - & - & - & 27,46 & 13,82 & 14,58 \\
\hline & $\mathrm{CV}$ & - & - & - & - & - & - & 4,30 & 28,16 & 39,24 \\
\hline \multirow{3}{*}{ V. de Córdoba } & $\mathrm{TN}$ & - & 63,89 & 45,14 & 44,42 & 42,64 & 23,89 & 46,45 & 44,00 & 47,02 \\
\hline & $\mathrm{TM}$ & - & - & - & 11,89 & 14,96 & 14,78 & 24,44 & 21,91 & - \\
\hline & $\mathrm{CV}$ & - & - & - & 32,54 & 27,68 & 9,11 & 22,01 & 22,09 & - \\
\hline \multirow{3}{*}{ V. del Rey } & TN & - & 13,41 & 15,66 & 13,08 & 25,15 & 44,87 & 39,65 & 37,04 & 49,71 \\
\hline & $\mathrm{TM}$ & - & - & - & - & 26,35 & 58,97 & 30,84 & 24,15 & 38,90 \\
\hline & $\mathrm{CV}$ & - & - & - & - & $-1,20$ & $-14,10$ & 8,81 & 12,88 & 10,81 \\
\hline \multirow{3}{*}{ GUADIATO } & $\mathrm{TN}$ & - & 22,92 & 29,98 & 20,21 & 31,45 & 33,68 & 33,00 & 31,40 & 35,05 \\
\hline & $\mathrm{TM}$ & - & - & - & - & 26,61 & 34,34 & 24,61 & 21,06 & 28,35 \\
\hline & $\mathrm{CV}$ & - & - & - & - & 4,84 & $-0,67$ & 8,39 & 10,34 & 6,69 \\
\hline \multirow{3}{*}{ PEDROCHES } & $\mathrm{TN}$ & - & 56,71 & 49,34 & 40,09 & 38,43 & 32,93 & 39,10 & 42,99 & 50,42 \\
\hline & $\mathrm{TM}$ & - & - & - & - & - & - & 25,95 & 17,87 & - \\
\hline & $\mathrm{CV}$ & - & - & - & - & - & - & 13,16 & 25,12 & - \\
\hline \multirow{3}{*}{ TOTAL } & $\mathrm{TN}$ & - & 39,82 & 39,66 & 30,15 & 34,94 & 33,30 & 36,05 & 37,19 & 42,73 \\
\hline & $\mathrm{TM}$ & - & - & - & - & - & - & 25,28 & 19,46 & - \\
\hline & $\mathrm{CV}$ & - & - & - & - & - & - & 10,77 & 17,73 & - \\
\hline
\end{tabular}

Nota: para las fechas de 1530, 1587, 1713 y 1752 se han transformado los vecinos en habitantes con un coeficiente de conversión de 3,95 para las villas del Guadiato y un módulo de 3,93 para los Pedroches, siguiendo el mismo criterio que se especifica en la nota $n^{\circ}$. 14. El cálculo de las medias comarcales y totales sólo se ha reflejado cuando están completas las series de cada localidad.

Fuente: elaboración propia a partir de los correspondientes Registros Parroquiales. 
mos que nos ofrece Valle (1985, pp. 309 y ss.). En los Municipios Mixtos el panorama es bien diferente: los de Villafranca y Hornachuelos desaparecieron incendiados, los de Almodóvar del Río se perdieron y los únicos conservados, que son los de Montoro, no pueden ser consultados. Por tanto, una parte considerable del territorio serrano adolecería del conocimiento y la explicación de su dinámica demográfica; sin embargo, no desconocemos la evolución de las cifras globales de población y además existen noticias históricas referentes a determinadas epidemias y crisis de subsistencia.

Las dificultades que aquejan a las series conservadas son diversas y se deben fundamentalmente al hecho de que comprenden un periodo de tiempo muy dilatado. La perdida de algunos libros o de parte de ellos, la ausencia de entierros hasta el siglo XVII o XVIII, en algunos casos, y el hecho de que las faltas se produzcan en algunos periodos intercensales de particular interés, rebaja el interés del estudio demográfico, puesto que no permite expresar la evolución continua de los movimientos naturales mediante las tasas respectivas. No obstante, en el cuadro 1 , se han calculado las series natalidad, mortalidad y crecimiento vegetativo de las villas citadas, que han conservado sus registros parroquiales, o parte de ellos, en las fechas que existen recuentos de población de esas mismas localidades.

\section{El siglo XVI}

El siglo XVI nos ofrece una imagen bastante positiva desde un punto de vista demográfico. Esto, que ya se apuntaba en las Contadurías Generales de 1530 y en el Censo de Tomás González de 1587, ahora queda suficientemente ratificado a la vista de las gráficas y cuadros de bautismos, matrimonios y defunciones de Belmez (figura 6), Fuente Obejuna (figura 7), Villanueva del Rey (figura 8), Hinojosa de Duque y Villanueva de Córdoba (Valle, 1985, pp. 310 y 311).

En efecto, todas las series muestran unos valores en alza en mayor o menor medida hasta finales de siglo, a partir de aquí comienza una caída acusada que no muestra síntomas de recuperación hasta inicios del siglo XvIII. Otro rasgo común es el perfil en forma de sierra que muestran los movimientos naturales, tanto en este periodo, como en los siglos siguientes, hasta bien entrado el siglo XIX y que es propio de lo que conocemos como el régimen demográfico antiguo.

A la vista de las gráficas, la falta de paralelismo resulta evidente, pudiéndose reseñar varios aspectos: las tasas de natalidad se mantiene altas, particularmente en los Pedroches (56,71\%o); el máximo de bautismos se alcanza primero en las villas del Guadiato, en Fuente Obejuna en 1560-1570, seguida 
FIGURA 6

EVOLUCIÓN ANUAL DEL NÚMERO DE BAUTIZOS, MATRIMONIOS Y SEPELIOS EN BELMEZ. PARROQUIA DE LA ANUNCIACIÓN (1521-1870)

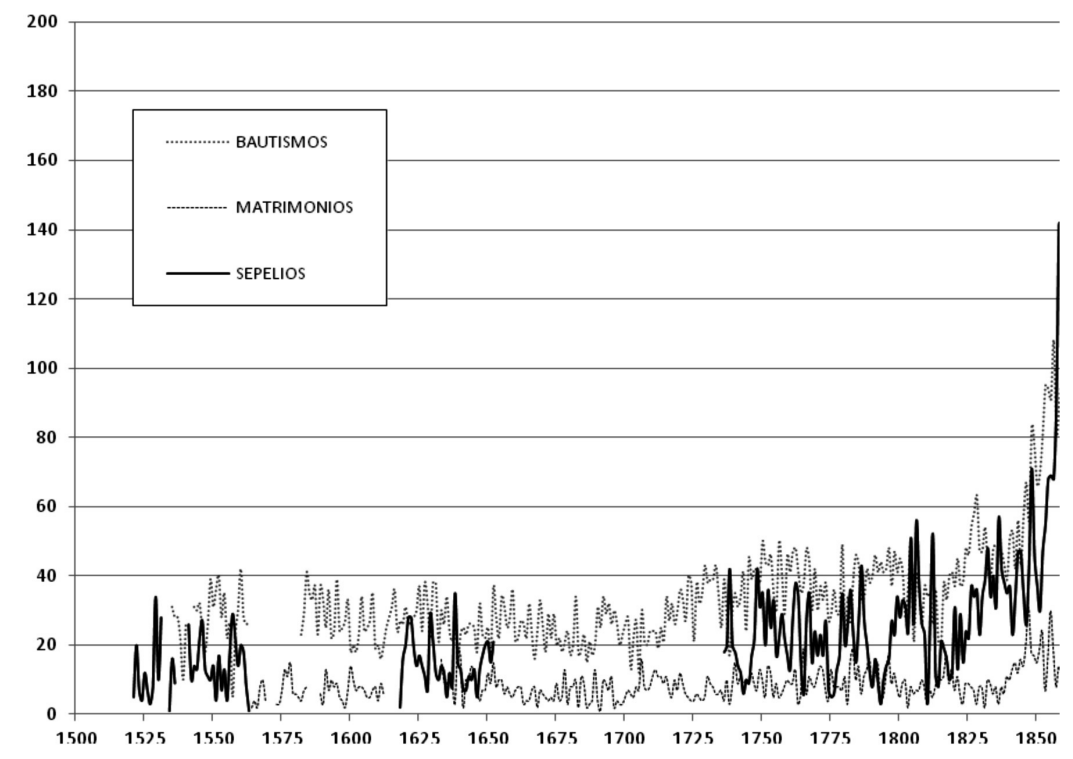

Fuente: elaboración propia a partir de los Libros Parroquiales.

de Belmez en torno a 1560 y Villanueva del Rey en 1570-1580. En las villas de los Pedroches es más tardío: en Hinojosa entre 1585 y 1595 y en Villanueva de Córdoba en 1610-1615. Esto hay que relacionarlo con el desarrollo y aparición más tardía de estas villas de los Pedroches, así como con las distintas cualidades agronómicas y con la condición realenga o señorial de cada localidad.

Solo contamos con los datos de entierros de Fuente Obejuna y Belmez, habiéndose perdidos los correspondientes libros de las demás parroquias. En el primer caso los registros se inician en 1573 y sin apenas omisiones. En el segundo parten ya desde 1521, aunque con notables lagunas como la de 1563 a 1619. En esta localidad, dentro de la propia irregularidad, no aparecen vértices muy agudos en los dos primeros tercios de siglo. En el último tercio y en Fuente Obejuna detestamos dos muy acusados: uno en 1580 con 226 difuntos, y otro en 1593 con 163. Ambas cimas ponen fin a una etapa expansiva de la natalidad y preceden al declive de los bautismos.

El factor demográfico más importante de este desequilibrio demográfico y que ocasiona los períodos de sobremortalidad, que jalonan el siglo XvI, es la 
peste. La peste aparece en Córdoba en cinco ocasiones (1506-1507, 1518, 1522-1524, 1582-1583 y 1601-1602) como señala Fortea (1981, pp. 177 y ss.), aunque Ballesteros (1982, pp. 102) apunta alguna más (1535-1536, 1551, $1560-1561$ y 1568). Los primeros brotes apenas dejaron huella en el marco rural, pero en 1583 se extendió por el Valle Oriental del Guadalquivir, próximo a Córdoba. Montoro (Ramírez, 1986, p. 353) y Adamuz ${ }^{17}$ se vieron afectadas, y más tarde, en 1601 lo fueron Fuente Obejuna y Villanueva del Rey. Los Pedroches al parecer escaparon a este ciclo epidemiológico. Recordemos que la mayor parte de epidemias de peste que padeció Andalucía en este siglo penetraron a través de los puertos mediterráneos (Domínguez, 1963, p. 68) y la provincia de Córdoba, situada en un valle ampliamente abierto al océano, no podía escapar a este tipo de contagio. No obstante la zona de la Sierra Norte y Sur de la provincia pareció evadirse en un principio a ella. Peso a todo, la de 1596 a 1602, que tenía un origen atlántico barrió casi por completo a la provincia.

Junto con las epidemias, las crisis de subsistencia fueron los agentes externos que más influyeron sobre la dinámica demográfica en este siglo y en los venideros. Aunque actuasen como factores autónomos, lo cierto es que cuando actuaban combinados los índices de mortalidad resultaban máximos.

\section{El siglo XVII}

El siglo XVII muestra una evolución demográfica bien distinta a la centuria anterior. Todas las gráficas muestran de forma clara el efecto que causan la peste, las inclemencias climáticas o las plagas sobre las curvas de bautismos, matrimonios y entierros.

Ya a finales del siglo anterior debieron haberse manifestado las crisis de subsistencia como indican las inflexiones de las líneas de bautismos de las distintas gráficas. Este fue el preámbulo de las continuas calamidades que azotarían el reino de Córdoba (Díaz, 1979, p. 64): peste en 1603, 1604, 1649, 1650, 1651 y 1682; exceso de lluvias en 1603, 1604, 1618, 1626, 1647, 1677, 1678, 1684 y 1691; sequías que ocasionan la perdida de las cosechas en 1605, 1616, $1617,1635,1636,1644,1652$, 1653, 1655, 1683, 1685, 1687, 1689, 1690, 1694, 1697 y 1700; plagas de langosta en 1618, 1619, 1708 y 1709; epidemia de palúdicas en 1679 y de tifoidea en 1684 .

${ }^{17}$ Ibíd., tom. I, p. 28. Este autor afirma que la población quedo reducida a 200 vecinos, dato poco probable si tenemos en cuenta que los censos de 1530 y 1587 atribuyen una población de 372 y 499 vecinos respectivamente. 
A mediados de siglo los pueblos más afectados por la peste fueron los de la Sierra, a partir de su presencia en Fuente Obejuna en 1648 (Ramírez, 1986, p. 72). Al año siguiente se extendió por los Pedroches (Alcaracejos, Belalcázar y a Villanueva de Córdoba) alcanzando a los núcleos limítrofes, y sólo en 1650-1651 reaparece en la campiña. En 1681-1682 alcanza a Montoro.

Las continuas epidemias y crisis de subsistencias que a menudo actuaban de forma combinada, debieron de suponer para las distintas comarcas mariánicas una sensible alteración del ritmo demográfico, máxime si tenemos en cuenta la precaria actividad agraria de la zona, debida a la fragilidad de los componentes ecológicos y a los condicionantes humanos e históricos. En efecto, la existencia de suelos escasamente desarrollados, con amplios periodos de reposo entre dos cosechas, la escasa superficie labrada y un clima que se manifiesta en este siglo con una gran irregularidad termopluviométrica, constituyen unos componentes ecológicos ciertamente negativos. Los componentes históricos y humanos también pesan negativamente, entre otros señalamos: los desequilibrios de la

\section{FIGURA 7}

EVOLUCIÓN ANUAL DEL NÚMERO DE BAUTIZOS, MATRIMONIOS Y SEPELIOS EN FUENTE OBEJUNA. PARROQUIA DE N. ${ }^{a}$ S. ${ }^{a}$ DEL CASTILLO (1546-1870)

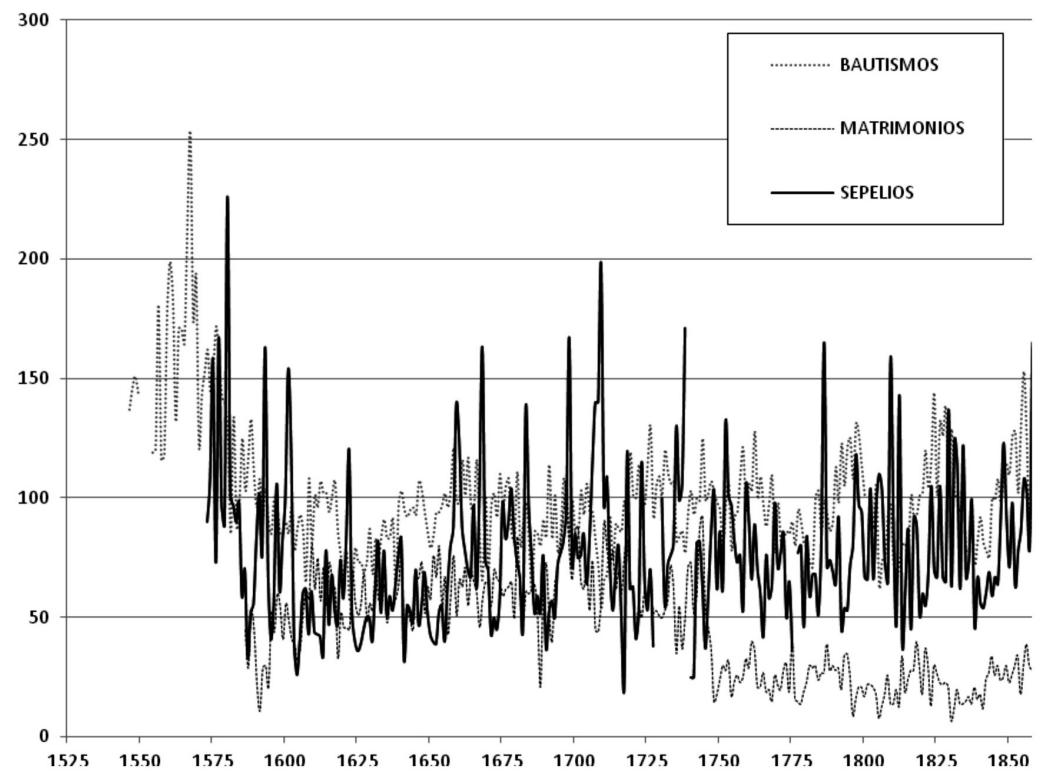

Fuente: elaboración propia a partir de los Libros Parroquiales. 
propiedad, la superficie labrada que se encontraba, mayoritariamente, en manos muertas o las deficitarias vías de comunicación.

Por su parte las parroquias de Belmez, Villanueva del Rey y Fuente Obejuna nos muestran un claro declive en el número de bautismos con mínimos, respectivamente, en los años: 1611-1639, 1622 y 1622 . No obstante el declive de las series no parece ser muy acusado en el conjunto de su evolución general y parece tocar fondo hacía 1620. Más bien podríamos hablar de una etapa de estancamiento demográfico, sin perder de vista el perfil en dientes de sierra propio de este régimen demográfico. Si comparamos dicho estancamiento y el que se registra también en la población de la capital cordobesa (Fortea, 1981, pp. 152 y ss.), destacan particularmente frente a la profunda y continuada crisis que afecto a Castilla (Reher, 1991, pp. 37 y ss.) durante el mismo periodo de tiempo.

En los Pedroches, aparecen de nuevo claramente diferenciadas las dos subcomarcas. Mientras que en Hinojosa el descenso es espectacular, en Villanueva de Córdoba la crisis parece casi inexistente. Esto fue debido a que en la

FIGURA 8

EVOLUCIÓN ANUAL DEL NÚMERO DE BAUTIZOS, MATRIMONIOS Y SEPELIOS EN VILLANUEVA DEL REY. PARROQUIA DE LA PURÍSIMA (1560-1870)

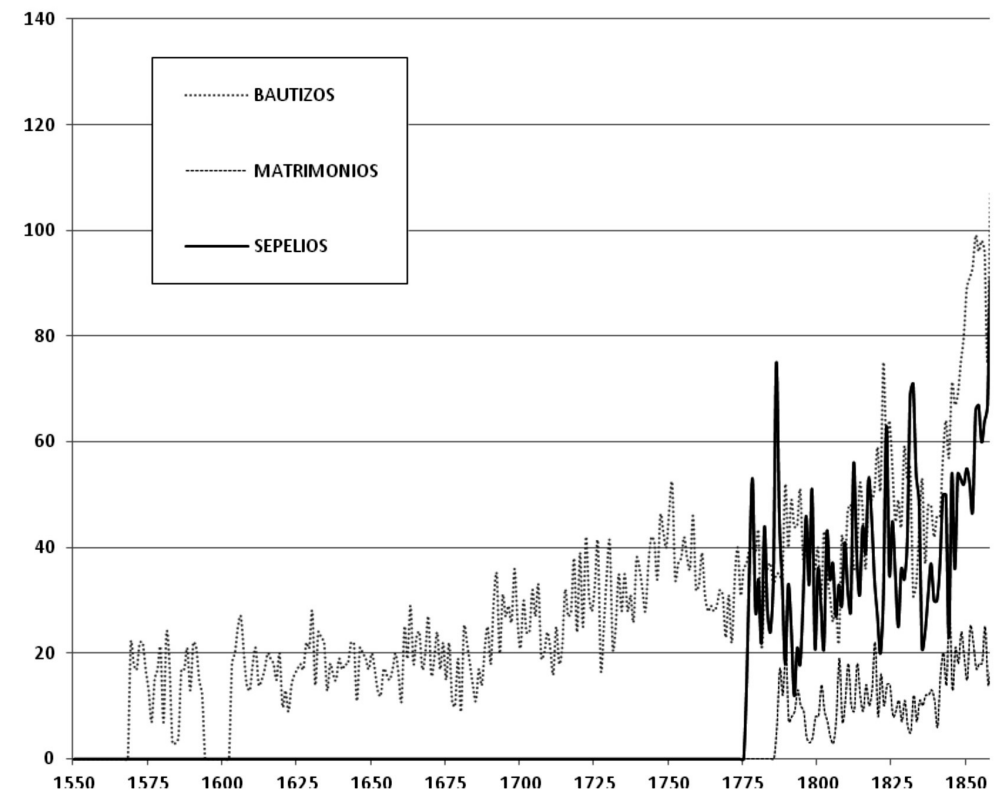

Fuente: elaboración propia a partir de los Libros Parroquiales. 
primera el régimen señorial actuó como «aliado de las restantes desdichas demográficas» y en la segunda se manifiestan «los baldíos y comunes como excelentes amortiguadores de las crisis» (Valle, 1985, p. 313). Así, la Sierra de Córdoba, como en el resto de Andalucía y las regiones de la «España periférica» (Nadal, 1988, pp. 42 y ss.), las series bautismales, a la baja desde el comienzo, tocan fondo más pronto y superan el bache en un intervalo de tiempo más corto, dentro de los límites del Seiscientos.

Las únicas series de entierros que se conservan para estas fechas son las de Fuente Obejuna y Belmez, la primera completa y la segunda sólo abarca el periodo de 1618 a 1652. En Fuente Obejuna son los años de 1659, 1668, 1683 y 1698 los de mayor mortandad. Las dos últimas fechas coinciden con sendas crisis de subsistencia que afectaron al conjunto del reino de Córdoba y se relacionan con períodos de sequía. En Belmez y en las fechas de 1621, 1629 y 1638 se duplica el número de difuntos de la villa.

Es a partir de 1640, aproximadamente, cuando podemos apreciar un progresivo distanciamiento de las curvas de nacimientos y matrimonios lo que indirectamente lleva a intuir el ascenso de la fecundidad a partir de esta fecha. Fortea (1981, p. 165) constata este hecho también en las parroquias de Córdoba ${ }^{18}$. En las gráficas de Hinojosa, Villanueva de Córdoba, Belmez y Fuente Obejuna es evidente; en la de Villanueva del Rey no contamos con datos de matrimonios hasta el último tercio del siglo XviII. Sobre este suceso de carácter cualitativo se va a fundamentar, en un principio, la expansión demográfica de la siguiente centuria.

\section{El siglo XVIII}

El siglo XVIII fue un periodo de recuperación demográfica para las comarcas mariánicas, al igual que en Andalucía y España. Los censos de 1713, 1752, 1781 y 1787 son de por sí bastante explícitos. En ellos se aprecia como la población serrana prácticamente se duplicó, aunque esta recuperación no afectó por igual a todas las comarcas. Los municipios mixtos fueron los más favorecidos, seguidos por los Pedroches y el Guadiato.

Las epidemias, y crisis de subsistencia todavía no desaparecerán, pero la mortalidad, aunque todavía anormal, ya no será tan catastrófica (Domínguez, 1981, pp. 142-144). La escasez y el hambre de 1709-1710 se dejan ver claramente en todas las gráficas, especialmente en el Guadiato, produciendo nu-

${ }^{18} \mathrm{El}$ autor señala los cocientes bautismos/matrimonios como significativos para detectar variaciones en la fecundidad, aunque apunta también otros factores como el retraso en la edad para contraer matrimonio o las migraciones. 
merosas muertes por inanición como se observa en la línea de defunciones de Fuente Obejuna que alcanza su cenit con 198 entierros en 1709. Una nueva crisis de subsistencia se manifestó en 1735-1738, siendo particularmente grave en Villanueva de Córdoba. La más tardía de 1754 se deja sentir en Hinojosa y en Fuente Obejuna.

Siguieron unos años apacibles hasta 1785-1787 en que la epidemia de tercianas y tabardillos hizo graves estragos entre la población. Pérez Moreda (1980, p. 342) contabiliza 10.937 difuntos en todo el reino de Córdoba. La epidemia palúdica ocasionó en 1786: 165 entierros en Fuente Obejuna, 43 en Belmez, 75 en Villanueva del Rey y 162 en Villanueva de Córdoba. El relato de Ocaña Prados (1982) resulta bastante esclarecedor de los efectos que ocasionaban la conjunción de la crisis de subsistencia con una epidemia, evidenciándose asimismo los condicionantes estructurales que afectaban a las comarcas mariánicas: la superpoblación ocasionada por el crecimiento demográfico de las últimas décadas, la dificultad en las comunicaciones, los bajos rendimientos agrícolas y los desequilibrios de la propiedad.

Las líneas de bautismos evidencian una progresiva elevación desde el año 1700 hasta 1800 aunque ensombrecidas por innumerables caídas que ralentizan el crecimiento vegetativo de las diferentes villas (cuadro 1). Así en Fuente Obejuna, en el primer tercio de siglo, hubo un crecimiento vegetativo en términos absolutos de 497 personas, en el segundo de 590 y en el tercero de 797. En Belmez, los bautismos se situaron casi siempre por encima de las defunciones incrementándose en los dos últimos tercios de siglo en unas mil cien personas. En Villanueva del Rey la diferencia es de sólo 167 en el último tercio. En Villanueva de Córdoba fue entre 1735 y 1786 cuando se consigue un mayor despegue de la natalidad, truncándose a partir de la fecha. En Hinojosa, en cambio se dio un crecimiento negativo en la segunda mitad de siglo.

La variable de matrimonios de las distintas gráficas muestra un mayor alejamiento de los bautismos, lo que evidencia un aumento de la fecundidad y un descenso de la mortalidad infantil con el consiguiente aumento de la natalidad, con valores altos que incluso superan el 50 por mil en recuperaciones coyunturales. Ésta se mantuvo sostenida en las villas estudiadas, aunque de forma más irregular ${ }^{19}$; con la excepción de Fuente Obejuna, donde desde mediados de siglo registra un descenso del 50\% manteniéndose esta dinámica en la siguiente centuria.

\footnotetext{
${ }^{19}$ No son infrecuentes valores del 40, o incluso de un 50 por mil, en villas como Belmez o Villanueva de Córdoba. Domínguez (1981, p. 137) constata este hecho en la población de la Baja Andalucía en ciertos momentos del siglo XviIl y que se relacionan con recuperaciones coyunturales de determinadas villas.
} 


\section{La primera mitad del siglo XIX}

Durante el siglo XIX la población siguió en aumento, pero sostenida por un régimen demográfico primitivo y sujeto a múltiples contingencias. La población total pasó de los 81.887 habitantes en 1826 a 146.977 en 1897 . Este incremento tan notable no estuvo acompañado por un cambio de las condiciones socioeconómicas de la zona, lo que ocasionó una superpoblación relativa y una especial sensibilidad demográfica. Tan sólo en el último tercio del siglo comenzaron a notarse los efectos de la desarmortización, a la vez que se desarrolla una importante actividad minera en la cuenca del Guadiato. Hechos estos que contribuirán de forma decisiva en el afianzamiento de un régimen demográfico moderno en la Sierra de Córdoba.

El siglo comenzó con la aparición de la fiebre amarilla, una nueva enfermedad endémica del oeste de África y de Centro y Sudamérica, que llega al puerto de Cádiz en 1800. Desde allí se propaga a Sevilla y a Jerez, y años más tarde a Córdoba. Ya desde 1800 se adoptaron medidas sanitarias para evitar el contagio, pero a pesar de todos los intentos de la Junta de Sanidad (Arjona, 1979, pp. 27 y ss.), creada a tal efecto, no se pudo evitar su llegada en 1804. Espejo, Montilla y otros pueblos de la Campiña fueron en los primeros afectados, junto con la capital a finales de ese año. Coincidió la epidemia con años de malas cosechas y a los pocos años vino a suceder la Guerra de Independencia, acompañada con la consecuente pérdida de cosechas, leva de hombres y requisa de granos; hechos que ocasionaron un hambre generalizada y aparición de nuevas epidemias como la de tifus que afecto a Belmez 1811 y que, según Casas-Deza (1986, p. 53) dejó reducida la población a 100 vecinos ${ }^{20}$.

En Villanueva de Córdoba se registró en 1804 una grave crisis de subsistencia, además de «fiebres perniciosas intermitentes» (Ocaña Prados, 1982, pp. 225-226), las cuales, más que corresponderse con la fiebre amarilla tienen su causa en un brote de malaria, puesto que el autor relata que se propuso un remedio basado en la quina. El resultado fue la emigración de unos 200 vecinos que pasaron a establecerse en la campiña (Ramírez, 1986, pp. 143).

En la década de 1830 aparece una nueva enfermedad, el cólera, esta vez procedente de oriente desde la península indostánica. Los primeros casos se detestan en Ayamonte y Huelva en agosto de 1833, alcanzando a la capital

${ }^{20}$ Afirmación un tanto exagerada de este autor, pues el libro parroquial contabiliza 27 defunciones ese año y 52 el siguiente. Datos no excesivamente catastróficos en una población que rondaba los mil habitantes. 
cordobesa y a otros pueblos limítrofes como Montoro y Villafranca a mediados de junio de 1834, unos días más tarde alcanzó a Pozoblanco. Según el Boletín Oficial de la Provincia de Córdoba fallecieron a causa de la enfermedad en Montoro 460 personas, en Villafranca 35 y en Pozoblanco 118. De este documento se desprende que la morbidad en los Pedroches y en el Guadiato fue escasa, a excepción de Pozoblanco. A pesar de ello, los libros parroquiales contabilizan 176 entierros en Villanueva de Córdoba, 40 en Belmez, 48 en Villanueva del Rey, 257 en Hinojosa y 122 en Fuente Obejuna, duplicándose la mortalidad habitual en las dos últimas villas. Aparecieron nuevos brotes de cólera morbo en la provincia en los años: 1854-1855, 1856, 1859-1860 y 1865. El primero afectó a Montoro y a Hinojosa donde dejo 211 difuntos, en su mayoría mujeres adultas (Valle, 1985, p. 319).

Pero no fueron la fiebre amarilla o el cólera los únicos «segadores» de los efectivos demográficos en este siglo XIX. Otras epidemias como la viruela o el sarampión actuaron de igual manera. Mencionemos la viruela que en 1839 azotó a Villanueva de Córdoba y que produjo 131 defunciones en su mayor parte entre los niños de menos de un año a cinco.

Otro caso destacado es el de Belmez en 1858, donde la acción combinada del sarampión, la viruela y la disentería a lo largo de los distintos meses del año son la causa principal de las 142 defunciones que contabiliza el libro parroquial. Si observamos la figura 9 apreciamos que es el sarampión la principal causa de defunción, si bien la incidencia de la misma resulta asimétrica en la pirámide de población así como en la distribución mensual de los entierros por esta causa. En la pirámide vemos como fueron los niños menores de cinco años los más afectados, registrándose solo algunos casos aislados en los escalones superiores. En la distribución anual de las enfermedades advertimos que se presenta de forma estacional, con máximos en verano y mínimos en invierno, aunque la enfermedad suele incubarse al final del invierno y comienzo de la primavera, presentando un patrón endémico con ciclos epidémicos bianuales. Los casos de viruela son también considerables en unas fechas en las que todavía no estaba extendida la vacuna ${ }^{21}$ contra este tipo de enfermedad, nuevamente se ceba en los más jóvenes, centrándose en los meses de invierno. Las disenterías están presentes durante casi todo el año aunque causan la ma-

${ }^{21}$ Hasta 1871 España no contó con un organismo estatal encargado de cultivar, difundir y controlar la vacuna antivariólica, nos referimos al Instituto de Vacunación del Estado; aunque las primeras fases del proceso de introducción de la vacuna de Edward Jenner en España ya se hubiesen iniciado a finales del siglo XVIII a cargo de F. Pigillem (1770-1826). 


\section{FIGURA 9} BELMEZ. EPIDEMIA DE SARAMPIÓN DE 1858. CAUSAS, DISTRIBUCIÓN
MENSUAL DE LOS ENTIERROS Y PIRÁMIDE DE DEFUNCIÓN
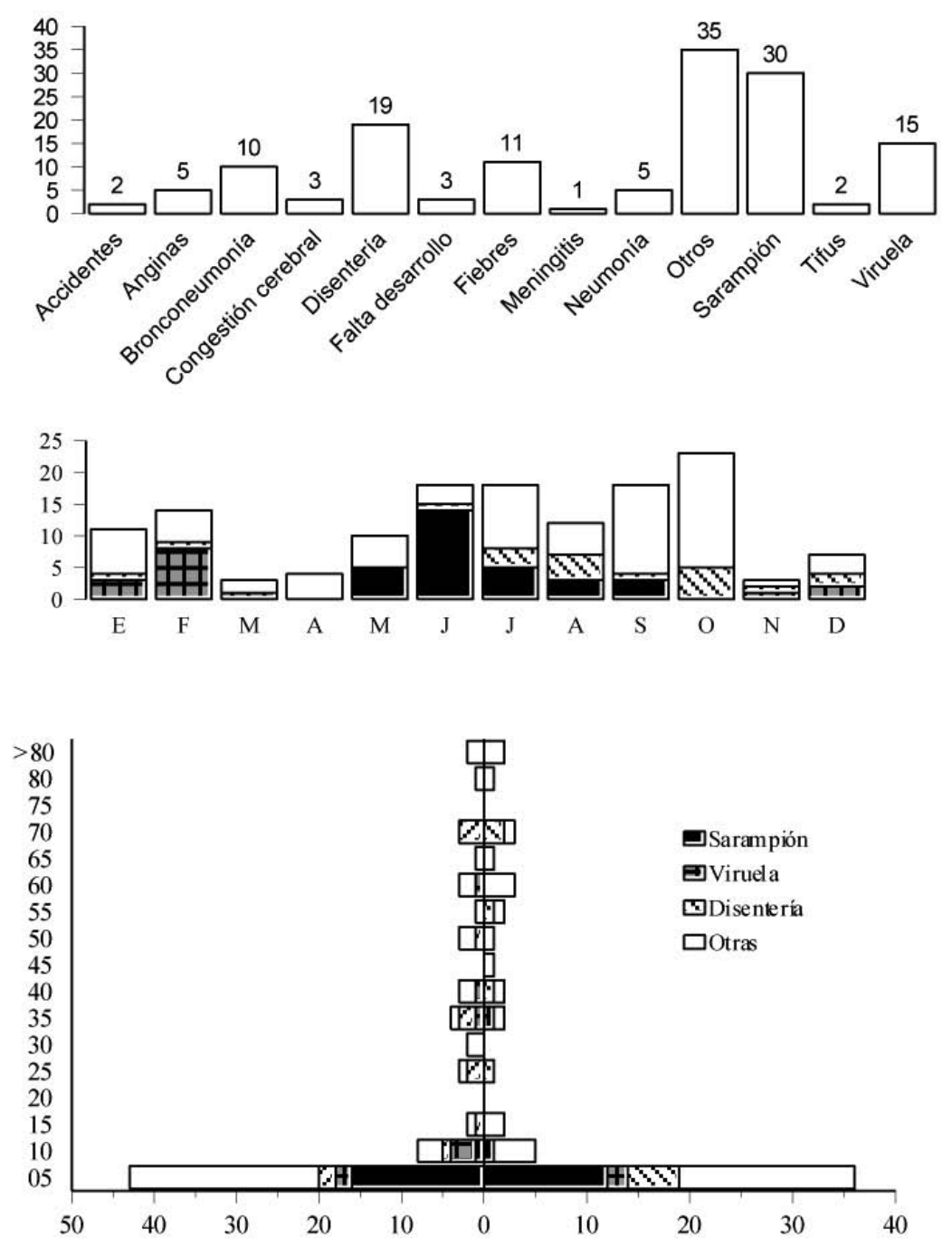

Pirámide de defunción

Fuente: elaboración propia a partir de los Libros de Sepelios. 
yor mortandad en los meses estivales y afectan particularmente a los niños y ancianos.

Se sucedieron también crisis de subsistencia tan mortíferas como las epidemias, por ejemplo la de 1837 en Hinojosa, en donde «Llovió tan poco... que ni brotaron ni echaron flor los arbustos, tales como las jaras...se murieron la mitad de las cabras y cerdos...» ${ }^{22}$.

Como podemos apreciar en todas las gráficas el número y la intensidad de los casos de mortandad catastrófica supera el de siglos anteriores. Esto contrasta, sobre todo, con la situación privilegiada, desde un punto de vista demográfico, en que se habían situado las comarcas mariánicas durante los siglos XVI y XVII. Su aislamiento fue la mejor defensa frente a las epidemias de sus vecinas -mejor comunicadas y más cercanas a los flujos comerciales de la época- La tendencia predominante a un alza continuada se vio truncada por constantes, bruscas y transitorias inflexiones que a menudo ocasionaban un crecimiento vegetativo negativo. Las variables de nupcialidad, influidas a su vez por estas contingencias, rompen con su tradicional moderación, acusando elevadas oscilaciones, a la vez que se sigue ensanchando el cociente bautismos/matrimonios, y por tanto se evidencia un incremento de la fecundidad.

Pese a las graves dificultades que mermaron a la población durante las primera mitad del siglo xix (mortalidad de un 25 por mil en 1826 y de un 19,46 por mil en 1840), se experimentó un notable crecimiento absoluto de la misma y un crecimiento vegetativo al alza ( 10,77 por mil en 1826 y 17,73 por mil en 1840). La clave estriba en el tono alcista de la natalidad a lo largo de todo el periodo (36,05 por mil en $1826,37,19$ por mil en 1840 y 42,73 por mil en 1848), gracias a las mejores condiciones higiénico-sanitarias y una mejor dieta alimenticia que fue paralela a la ampliación de la superficie de cultivo en las comarcas mariánicas.

\section{CONCLUSIÓN}

En conclusión, la evolución demográfica durante el periodo que abarca desde el primer tercio del siglo XVI hasta mediados del siglo XIX se caracteriza por un conjunto de hechos que resultan del máximo interés para una acertada comprensión de la población y del poblamiento mariánico:

${ }^{22}$ Libro $5^{\circ}$ de Entierros. Archivo Parroquial de Hinojosa el Duque. Anexo, sin numerar. 
- En primer lugar, resulta posible un conocimiento de los hechos demográficos, parcial, aunque bastante aproximado, gracias al concurso de la fuentes denominadas «precensales».

- Desde un punto de vista cuantitativo, la población de la sierra norte cordobesa experimenta un continuo crecimiento, pasando de 9.150 a 19.304 vecinos, crecimiento que hizo posible un cenit de ocupación, alcanzándose una densidad de $9,27 \mathrm{hab} / \mathrm{km}^{2}$. Si bien dicho incremento tan solo se operó a razón de un $0,24 \%$ anual.

- Este despegue demográfico debemos relacionarlo con el proceso de modernización demográfica en España que se realizó a un ritmo más lento que en los países vecinos, dándose el caso de que en la Sierra este retraso fue aún mayor.

- Es así como la Sierra Morena Cordobesa se configura como un espacio interior y que subsiste en el conjunto de la provincia con una densidad de población inferior en razón de sus componentes ecológicos, débiles aprovechamientos agropecuarios y una expansión demográfica más acompasada.

- Fue un hecho de carácter estrictamente demográfico, como el descenso de las tasas de mortalidad, lo que incidió de forma directa en el positivo crecimiento vegetativo de la población. Lo que se debió, por otro lado, a un combinado de circunstancias de tipo socioeconómico que mejoraron las condiciones de vida de los vecinos que poblaban Sierra Morena.

- En líneas generales, podemos decir que la evolución demográfica y los resultados del análisis de los movimientos naturales, en los espacios mariánicos de la provincia de Córdoba, vienen a coincidir con las tendencias descritas, para la región en la que se insertan, por aquellos autores ya reseñados en la bibliografía. Todo ello salvando las diferencias intercomarcales e intracomarcales, conscientes de que la autarquía de esta zona interior, y bastante más incomunicada que el resto del valle del Guadalquivir, fue no solamente económica sino, en buena parte, también demográfica.

- Con respecto al poblamiento, las villas que ostentaron la capitalidad histórica y un mayor volumen demográfico la mantendrán hasta el final del periodo en el caso de Fuente Obejuna y Montoro. En tanto, Belalcázar lo hizo a favor de Hinojosa del Duque y Pedroche a favor de Pozoblanco y Villanueva de Córdoba. 


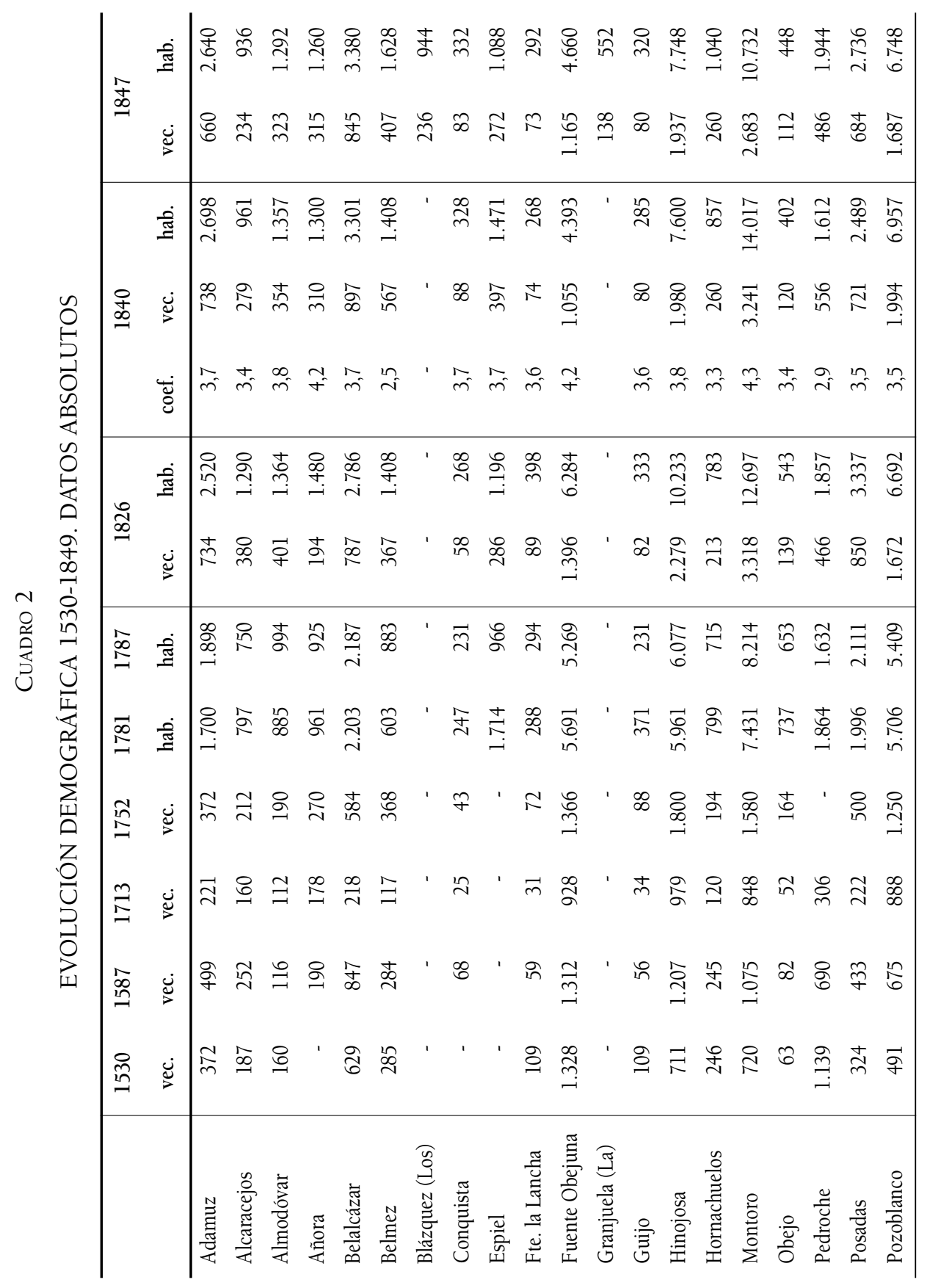

Estudios Geográficos, Vol. LXXIV, 274, pp. 115-151, enero-junio 2013 ISSN: 0014-1496, eISSN: 1988-8546, doi: 10.3989/estgeogr.201305 


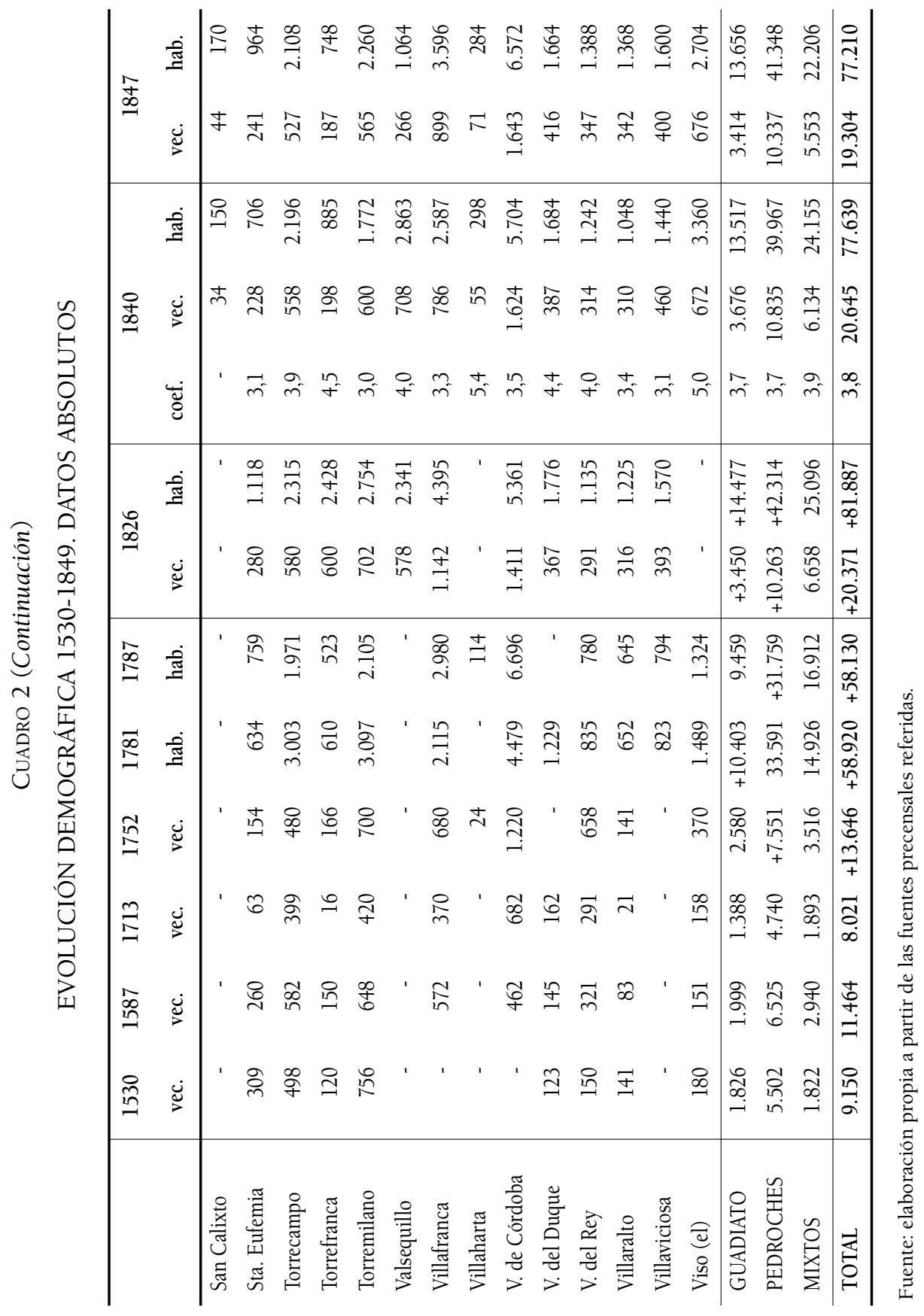

Estudios Geográficos, Vol. LXXIV, 274, pp. 115-151, enero-junio 2013 ISSN: 0014-1496, eISSN: 1988-8546, doi: 10.3989/estgeogr.201305 
CuAdro 3

EVOLUCIÓN DEMOGRÁFICA 1530-1849

\begin{tabular}{|c|c|c|c|c|c|c|c|c|c|}
\hline & 1530 & 1587 & 1713 & 1752 & 1781 & 1787 & 1826 & 1840 & 1847 \\
\hline Adamuz & 100 & 134 & 59 & 100 & 124 & 138 & 197 & 198 & 177 \\
\hline Alcaracejos & 100 & 135 & 86 & 113 & 125 & 118 & 203 & 149 & 125 \\
\hline Almodóvar & 100 & 72 & 70 & 119 & 151 & 163 & 251 & 221 & 202 \\
\hline Añora & - & 100 & 94 & 142 & 121 & 116 & 102 & 163 & 166 \\
\hline Belalcázar & 100 & 134 & 34 & 93 & 94 & 95 & 125 & 143 & 134 \\
\hline Bélmez & 100 & 100 & 41 & 129 & 85 & 124 & 129 & 199 & 143 \\
\hline Blázquez (Los) & - & - & - & - & - & - & - & - & - \\
\hline Conquista & - & 100 & 37 & 63 & 99 & 92 & 85 & 129 & 122 \\
\hline Espiel & - & - & - & - & 100 & 56 & 70 & 86 & 59 \\
\hline Fte. la Lancha & 100 & 54 & 28 & 66 & 73 & 75 & 82 & 68 & 67 \\
\hline Fuente Obejuna & 100 & 99 & 70 & 103 & 102 & 94 & 105 & 78 & 88 \\
\hline Granjuela (la) & - & - & - & - & - & - & - & - & 100 \\
\hline Guijo & 100 & 51 & 31 & 82 & 97 & 61 & 75 & 73 & 73 \\
\hline Hinojosa & 100 & 170 & 137 & 253 & 221 & 225 & 320 & 278 & 272 \\
\hline Hornachuelos & 100 & 99 & 49 & 79 & 98 & 88 & 87 & 106 & 106 \\
\hline Montoro & 100 & 149 & 118 & 219 & 240 & 265 & 461 & 450 & 373 \\
\hline Obejo & 100 & 130 & 83 & 260 & 354 & 314 & 221 & 190 & 177 \\
\hline Pedroche & 100 & 61 & 27 & - & 56 & 49 & 41 & 49 & 43 \\
\hline Posadas & 100 & 134 & 69 & 154 & 176 & 186 & 262 & 223 & 211 \\
\hline Pozoblanco & 100 & 137 & 181 & 315 & 332 & 315 & 340 & 406 & 344 \\
\hline San Calixto & - & - & - & - & - & - & - & 100 & 129 \\
\hline Santa Eufemia & 100 & 84 & 20 & 50 & 66 & 79 & 91 & 74 & 78 \\
\hline Torrecampo & 100 & 117 & 80 & 96 & 155 & 101 & 116 & 112 & 106 \\
\hline Torrefranca & 100 & 125 & 13 & 138 & 113 & 95 & 500 & 165 & 156 \\
\hline Torremilano & 100 & 86 & 56 & 93 & 141 & 96 & 93 & 79 & 75 \\
\hline Valsequillo & - & - & - & - & - & - & 100 & 122 & 46 \\
\hline Villafranca & - & 100 & 65 & 119 & 112 & 158 & 200 & 137 & 157 \\
\hline Villaharta & - & - & - & 100 & - & 88 & - & 229 & 305 \\
\hline V. de Córdoba & - & 100 & 148 & 264 & 277 & 414 & 305 & 352 & 355 \\
\hline V. del Duque & 100 & 118 & 132 & - & 232 & - & 298 & 314 & 338 \\
\hline V. del Rey & 100 & 214 & 194 & 438 & 139 & 130 & 194 & 209 & 231 \\
\hline Villaralto & 100 & 59 & 15 & 100 & 140 & 139 & 224 & 220 & 242 \\
\hline Villaviciosa & - & - & - & - & 100 & 96 & 191 & 173 & 151 \\
\hline Viso (El) & 100 & 84 & 88 & 205 & 165 & 147 & - & 373 & 376 \\
\hline$\overline{\text { GUADIATO }}$ & 100 & 109 & 76 & 141 & +150 & 137 & +190 & 202 & 188 \\
\hline PEDROCHES & 100 & 119 & 86 & +137 & 171 & +156 & +187 & 197 & 188 \\
\hline MIXTOS & 100 & 161 & 104 & 193 & 210 & 238 & 365 & 337 & 305 \\
\hline TOTAL & 100 & 130 & 89 & +157 & +177 & +177 & +247 & 245 & 227 \\
\hline
\end{tabular}

Nota: Números índice con base $1530=100$.

Fuente: elaboración propia a partir de las fuentes precensales referidas.

Estudios Geográficos, Vol. LXXIV, 274, pp. 115-151, enero-junio 2013

ISSN: 0014-1496, eISSN: 1988-8546, doi: 10.3989/estgeogr.201305 
Fecha de recepción: 14/11/2011

Fecha de aceptación: 28/11/2012

\section{BIBLIOGRAFÍA}

Arjona Castro, A. (1979): La población de Córdoba en el siglo XIX. Sanidad y crisis demográfica en la Córdoba decimonónica. Córdoba, Instituto de Historia de Andalucía.

Ballesteros Rodríguez, J. (1982): La peste en Córdoba. Córdoba, Diputación Provincial. Bernal, A. M. (1981): “Andalucía Occidental Economía rural 1590-1765”, en J. E. López de Coca Castañer (dir.): Historia de Andalucía. V. Los inicios del capitalismo (1621-1778). Barcelona, CUPSA, 1981, pp. 185-242.

Bustelo García del Real, F. (1973): "La transformación de vecinos en habitantes. El problema del coeficiente". Estudios Geográficos, 130, pp. 154-164.

Cabrera Muñoz, E. (1978): "Tierras realengas y tierras de señorío en Córdoba a fines de la Edad Media. Distribución geográfica y niveles de doblamiento", en E. Cabrera Muñoz (ed.): Actas del I Congreso de Historia de Andalucía. Andalucía Medieval, I. Córdoba, Monte de Piedad y Caja de Ahorros, pp. 295-308.

Díaz del Moral, J. (1979): Historia de las agitaciones campesinas andaluzas. Alianza, Madrid.

Domínguez Ortiz, A. (1981): "La población de la Baja Andalucía", en E. López de Coca Castañer (dir.): Historia de Andalucía. V. Los inicios del capitalismo (16211778). Barcelona, CUPSA, pp. 133-156.

Domínguez Ortiz, A. (1963): La sociedad española del siglo XVII. CSIC, Madrid, 1963.

Fernández Álvarez, M. (1979): España y los españoles en los tiempos modernos. Salamanca, Universidad.

Flores Varela, C. (2005): "La evolución de la población urbana de Andalucía en los siglos XV y XVI”. La España Medieval, 28, pp. 97-125.

Fortea Pérez, J. I. (1981): Córdoba en el siglo XVI: Las bases demográficas y económicas de una expansión urbana. Córdoba, Monte de Piedad y Caja de Ahorros.

González, T. (1829): Censo de las provincias y partidos de la Corona de Castilla. Madrid, Imprenta Real, 399 pp.

Madoz, P. (1845): Diccionario geográfico-estadístico-histórico de España y sus posesiones de ultramar. Madrid, Est. literario-tipográfico de P. Madoz y L. Sagasti.

Miñano, S. de (1826-1828): Diccionario geográfico-estadístico de España y Portugal. Madrid.

Nadal Oller, J. (1988): "La población española durante los siglos XVI, XVII y XVIII. Un balance a escala regional", en V. Pérez Moreda y D. Reher (coords.): Demografía histórica en España. Madrid, Ed. El Arquero, pp. 39-54.

Nicolau Nos, R. (1991): "Trayectorias regionales en la transición demográfica española”, en Instituto de Cultura Juan Gil Albert (ed.): Actas del II Congreso de la Aso- 
ciación de Demografía Histórica. Vol. 2. Alicante, Instituto de Cultura Juan Gil Albert, Alicante, pp. 49-65.

Nieto Cumplido, M. (1978): "Nuevas Fuentes Precensales del Obispado de Córdoba". B.R.A.C., 98, pp. 157-171.

Ocaña Prados, J. (1982): Historia de la villa de Villanueva de Córdoba. Córdoba, Ayuntamiento de Villanueva de Córdoba.

Ocaña Torrejón, J. (1962): Historia de la villa de Pedroche y su comarca. Córdoba, Tip. Artística.

Pérez García, J. M. (1995): "La evolución de la población andaluza en la Edad Moderna", en Junta de Andalucía (ed.): Actas del II Congreso de Historia de Andalucía. Historia Moderna, I. Córdoba, Consejería de Cultura y Medio Ambiente de la Junta de Andalucía y Cajasur, pp. 29-47.

Pérez Moreda, V. (1980): Las crisis de mortalidad en la España Interior (Siglos XVI-XIX). Madrid, Siglo XXI.

Ponsot, P. (1986): Atlas de Historia Económica de la Baja Andalucía (Siglos XVI-XIX). Sevilla, Editoriales Andaluzas Unidas.

Ramírez y de Las Casas-Deza, L. M.a (1986): Corografía histórico-estadística de la provincia y obispado de Córdoba. Córdoba, Monte de Piedad y Caja de Ahorros de Córdoba.

Ramírez y de las Casas-Deza, L. M. (1840): Corografía histórico-estadística de la provincia y obispado de Córdoba. Córdoba, Im. de Noguer y Manté, 472 pp.

Reher, D. (1991): "Dinámicas demográficas en Castilla La Nueva, 1550-1900: un ensayo de reconstrucción", en J. Nadal Oller (dir.): Evolución demográfica bajo los Austrias. Actas del II Congreso de la Asociación de Demografía histórica. Vol. 3. Alicante, Instituto de Cultura Juan Gil Albert, pp. 17-75.

Romero de Solís, P. (1973): La población española de los siglos XVIII y XIX. Estudio de sociodemografía histórica. Madrid, Siglo XXI.

Ruiz Martín, F. (1967): "La población española al comienzo de los tiempos modernos". Anexos de la Revista Hispania, 1, pp. 189-202.

Valle Buenestado, B. (1985): Geografía Agraria de los Pedroches. Córdoba, Diputación Provincial de Córdoba.

\section{RESUMEN}

La Sierra de Córdoba constituye un ámbito espacial diferenciado en la provincia y en el conjunto de la Península. El estudio de la dinámica demográfica en la etapa precensal y las diferencias regionales que presentan constituyen los objetivos principales del presente trabajo. Desde un punto de vista cuantitativo la población experimenta un crecimiento que hizo posible un cenit de ocupación. Este despegue demográfico sin precedentes en las comarcas estudiadas debemos relacionarlo con el proceso de evolución demográfica positiva que pese a todo, en estos espacios interiores, se realizó a un ritmo inferior. 
Palabras Clave: Demografía histórica; Fuentes demográficas; Sierra Morena, Córdoba.

\section{Abstract}

The Sierra of Cordoba is a spatial area that is differentiated within the province and in the whole of the Peninsula. The study of population dynamics in the pre-census stage and the regional differences that they present constitute the main objectives of the present study. From a quantitative point of view the population experienced a growth which made a zenith of occupation possible. In the municipalities included in this study we relate this unprecedented demographic takeoff to the process of positive demographic development which took place at a lower rate in these interior spaces in spite of everything.

KEY WORDS: Historical demography; Demographic Sources; Sierra Morena; Córdoba.

\section{RÉSUMÉ}

La Sierra de Córdoba constitue un domaine spatial différencié, non seulement dans la région mais aussi dans l'ensemble de la péninsule Ibérique. Létude de la dynamique démographique pendant la période préalable au recensement, ainsi que des différences régionales existantes, constitue le principal objectif de cette étude. D’un point de vue quantitatif, la population connait une croissance qui a rendu possible une occupation maximale. Cet essor démographique sans précédents dans les régions étudiées doit être mis en rapport avec le processus d'évolution démographique positif qui, malgré tout, s'est produit à un rythme plus lent dans ces espaces intérieurs.

Mots ClÉs: démographie historique; sources démographiques; Sierra Morena; Cordoue. 